\title{
The Macroeconomics of Shadow Banking
}

\author{
Alan Moreira and Alexi Savov*
}

January 2014

\begin{abstract}
We build a macroeconomic model of financial intermediation in which intermediaries issue equity without friction. In normal times, they maximize liquidity creation by levering up the collateral value of their assets, a process we call shadow banking. A rise in uncertainty causes investors to demand liquidity in bad states, which forces intermediaries to delever and substitute toward safe liabilities; shadow banking shuts down, prices and investment fall. The model produces slow economic recoveries, especially when intermediaries are highly-capitalized. It features collateral runs and flight to quality, and it provides a framework for analyzing unconventional monetary policy and regulatory reform proposals.
\end{abstract}

JEL: E44, E52, G21

Keywords: Macro finance, shadow banking, financial intermediation.

\footnotetext{
*Moreira is at Yale University School of Management, alan.moreira@yale.edu. Savov is at New York University Stern School of Business, asavov@stern.nyu.edu. We thank participants at the Yale Finance Brown Bag, the 2013 Kellogg Junior Finance Conference, the Fall 2013 NBER Monetary Economics Program Meeting, as well as seminar participants at the Kellogg School of Management and Wisconsin School of Business. We thank Markus Brunnermeier, Gary Gorton, Arvind Krishnamurthy, Matteo Maggiori, Andrew Metrick, Tyler Muir, Thomas Phillipon, and Michael Woodford for suggestions. We welcome further suggestions and comments.
} 
Economic performance over the last ten years tells the story of a boom, a bust, and a slow recovery. Recent research highlights the role of the financial sector in amplifying the bust of 2007-2009. Yet there is also an understanding that the connection between macro and finance runs deeper: The ups and downs of the recent cycle closely track the rise and fall of shadow banking. ${ }^{1}$ The capital-scarcity view of Kiyotaki and Moore (1997) and Bernanke, Gertler, and Gilchrist (1999), and its intermediary-centric formulation in He and Krishnamurthy (2012) and Brunnermeier and Sannikov (2013), among others, does not offer an interpretation of shadow banking that can be used to draw this connection. The question arises, what are the macroeconomic effects of shadow banking?

We propose a dynamic macroeconomic model that reproduces key features of the full 2003-2013 cycle - including the buildup of fragility in the boom and the slow recovery after the bust - as a result of the rise and fall of shadow banking. We interpret shadow banking as the process of creating securities that are money-like in normal times but become illiquid in a crash. We call such securities shadow money (repurchase agreements and asset-backed commercial paper provide useful examples) in contrast to money which is always liquid. Agents use liquid assets to insure against shocks that force them to quickly liquidate part of their wealth. Shadow banking transforms illiquid productive assets into liquid securities that meet this demand.

A prolonged quiet period like the Great Moderation leads investors to anticipate low economic uncertainty. The spread between shadow money and money falls, making collateral transformation increasingly profitable. The shadow banking sector enters a boom and

\footnotetext{
${ }^{1}$ From Bernanke (2013): "Shadow banking... was an important source of instability during the crisis.... Shadow banking includes vehicles for credit intermediation, maturity transformation, liquidity provision, and risk sharing. Such vehicles are typically funded on a largely short-term basis from wholesale sources. In the run-up to the crisis, the shadow banking sector involved a high degree of maturity transformation and leverage. Illiquid loans to households and businesses were securitized, and the tranches of the securitizations with the highest credit ratings were funded by very short-term debt, such as asset-backed commercial paper and repurchase agreements (repos). The short-term funding was in turn provided by institutions, such as money market funds, whose investors expected payment in full on demand and had little tolerance for risk to principal.... When investors lost confidence in the quality of the assets... they ran. Their flight created serious funding pressures throughout the financial system, threatened the solvency of many firms, and inflicted serious damage on the broader economy."
} 
liquidity becomes abundant. Greater liquidity encourages saving, lowering discount rates and raising asset prices, investment, and growth. The effect is greatest for productive but risky assets whose collateral value is low. As a result, in quiet periods the financial sector drifts toward shadow banking and the economy drifts toward a riskier but more productive capital stock. Over time, this process builds up economic fragility.

A series of uncertainty shocks like the ones that began in July 2007 and culminated in September 2008 set off a chain of events in securities and asset markets. ${ }^{2}$ Higher uncertainty reduces the substitutability between shadow money and money in the provision of liquidity, causing the spread between them to open up. Intermediaries respond by retiring shadow money from their balance sheets and replacing it with money, which requires deleveraging. Shadow banking markets dry up. The supply of liquidity falls, discount rates rise, and aggregate prices fall. A flight to quality effect pushes up the prices of safe assets as collateral becomes more scarce. ${ }^{3}$

Our model generates slow recoveries as the occurrence of a crash increases the perceived likelihood of future crashes due to learning. ${ }^{4}$ As uncertainty grows, good collateral becomes ever scarcer and the economy's optimal capital mix swings towards safety. Transition to the new target is slowed by technological illiquidity. Investment in productive but risky projects plummets, depressing growth. Intermediaries hoard unproductive safe assets, issuing money to meet demand for crash-proof liquidity and equity to back it up; high levels of intermediary equity capital accompany low growth, not high. Even a highly liquid economy is slow-

\footnotetext{
${ }^{2}$ In July 2007, two Bear Stearns hedge funds failed. We think of this episode as exemplifying the uncertainty shocks in our model. The Financial Crisis Inquiry Report (2011) refers to it as "a canary in the mineshaft," borrowing the phrase from a Wall Street insider. At the FOMC meeting in June, Boston Fed President Cathy Minehan also expressed a sense of uncertainty, "While the Bear Stearns hedge fund issue may well not have legs, the concerns regarding valuation of the underlying instruments do give one pause. Can markets adequately arrive at prices for some of the more exotic CDO tranches? What happens when the bottom falls out and positions thought to be at least somewhat liquid become illiquid? Is there a potential for this to spread and become a systemic problem?" (Federal Open Market Committee 2007).

${ }^{3}$ See Krishnamurthy (2010) and McCauley and McGuire (2009) for evidence of flight to quality in US Treasury and foreign exchange markets during the 2008 financial crisis.

${ }^{4}$ In our model, uncertainty jumps most from a low level, in the spirit of a "Minsky moment" (Minsky 1986). Since the collapse of Lehman Brothers in September 2008, there have been persistent fears of aftershocks, including European sovereign defaults, a break-up of the Euro currency, the U.S. debt ceiling crisis, and a slow-down in emerging markets.
} 
growing when liquidity is produced directly from safe assets rather than through collateral transformation of productive assets. A "fortress balance sheet", whether on the assets or liabilities side, is a sign of low liquidity transformation and results in low growth.

In contrast to the existing macro-finance literature, our model does not draw any distinction between inside and outside sources of funding. Intermediaries are free to change their capital structures at no cost as long as they have the assets to back their promises. They do so in response to investor demand for liquidity as reflected in funding spreads between money, shadow money, and equity. The financial sector is competitive so funding costs alone drive today's issuance and investment decisions which determine the economy's risk profile tomorrow. Asset prices capitalize the future path of the supply of liquidity. In short, intermediaries in our model are not special, intermediation is.

Our model generates amplification via endogenous "collateral runs", positive reinforcement between prices and haircuts (Brunnermeier and Pedersen 2009). Uncertainty shocks cause shadow banking to contract, reducing liquidity and raising discount rates. A collateral run occurs when this rise in discount rates is accelerating so that as an asset's price today falls, its worst-case price tomorrow falls even more. This happens near the top of the credit cycle when uncertainty shocks get progressively larger yet prices remain exposed so that the near-term worst-case scenario for valuations is deteriorating; i.e. "the bottom is dropping out." In our model collateral runs are a consequence of shadow banking.

Central to our analysis is the endogenous evolution of the economy's sensitivity to uncertainty shocks, which arises from the liquidity transformation decisions of intermediaries. Shadow banking increases liquidity provision in low-uncertainty states, boosting asset prices and setting the economy on a path to a riskier but more productive capital mix. The increased liquidity and risky capital, however, cannot be supported when uncertainty rises and investor demand turns to crash-proof liquidity, even as intermediaries strive to absorb this demand by crash-proofing their balance sheets. By their actions, intermediaries cause prices and investment to increase at the top of the credit cycle while cushioning their fall near the 
bottom.

We use the model to examine the implications for liquidity provision of various policy interventions. Our analysis shows that large-scale asset purchases (LSAP) can help increase the supply of scarce good collateral in a crisis, stabilizing markets. A mistimed intervention, an early exit, or talk of an early exit (i.e. "tapering"), can each undo the effectiveness of LSAP. Other policies like "Operation Twist" can be counter-productive as they syphon off long-duration safe assets that act as uncertainty hedges on intermediary balance sheets. Regulatory reform in the spirit of the "Volcker rule" or the Glass-Steagall Act, which we interpret as the mandatory segregation of safe and risky assets, can reduce efficiency as flight-to-quality effects create complementarities between assets in the production of liquidity services. Stricter capital requirements like those proposed by the Basel Committee reduce asset price volatility but they also reduce the supply of liquidity which raises the cost of capital.

The rest of the paper is organized as follow: Section 1 reviews the literature, Section 2 presents the model, Section 3 presents results from a numerical implementation, Section 4 contains policy analysis, and Section 5 concludes.

\section{Related literature}

Our paper lies at the intersection of the traditional banking literature and the growing macrofinance literature. Our starting point are the insights of Diamond and Dybvig (1983) and Gorton and Pennacchi (1990). As in Diamond and Dybvig (1983), financial intermediaries add value only to the extent that their liabilities are more liquid than their assets. As in Gorton and Pennacchi (1990), liabilities are liquid only if their valuations are insensitive to information. Our principal contribution is to incorporate this liquidity provision view of banking into a macro-finance framework.

So far, the emphasis in the macro-finance literature has been on the scarcity of en- 
trepreneurial or intermediary capital in amplifying and propagating fundamental shocks (for a recent survey, see Brunnermeier, Eisenbach, and Sannikov 2012). In Bernanke and Gertler (1989) and Bernanke, Gertler, and Gilchrist (1999), funding costs are decreasing in entrepreneurial net worth. In our paper, equity markets are frictionless so net worth plays no role, but issuing liquid debt lowers funding costs as a result of household demand for liquidity. The two approaches produce opposite results: funding costs in our model are minimized when equity is low, not high.

In Kiyotaki and Moore (1997), external funding is limited by the availability of collateral. Similar constraints arise in Geanakoplos (2003), Gertler and Kiyotaki (2010), Gertler and Kiyotaki (2013), Rampini and Viswanathan (2012), Brunnermeier and Sannikov (2013), Sannikov (2013), Maggiori (2013), and Simsek (2013). In these papers, collateral values limit debt and equity issuance alike, whereas here they only limit issuance of liquid debt. Our collateral constraint therefore affects funding costs rather than funding amounts, and it allows us to make equity issuance costless.

The collateral constraint (i.e. limited liability), the household demand for liquidity, and the either-or nature of the liquidity attribute (a claim is either liquid or not) break the assumptions of Modigliani-Miller (Modigliani and Miller 1958) and give intermediaries a role in tranching assets. ${ }^{5}$ DeAngelo and Stulz (2013) applies this same logic to show that high intermediary leverage can be socially valuable. In contrast, the macro-finance literature generally relies on differences in preferences (e.g. Geanakoplos 2003), expertise (e.g. Kiyotaki and Moore 1997), or on limited participation (e.g. He and Krishnamurthy 2012). We view our framework as best suited specifically for analyzing the liquidity transformation role of banks.

Our model delivers a fully dynamic and endogenous version of the collateral run amplification mechanism in Brunnermeier and Pedersen (2009). We find that collateral runs occur only after a shadow banking boom, when liquidity provision is maximally stretched relative

\footnotetext{
${ }^{5}$ Limited liability must also apply to households' direct capital holdings (though not their securities holdings) so they cannot short capital to synthetically create more assets for intermediaries to tranche.
} 
to the availability of collateral, making prices highly exposed to uncertainty shocks.

Recent macro models based on the information sensitivity view of liquidity (Gorton and Pennacchi 1990) include Gorton and Ordoñez (2012) and Dang, Gorton, and Holmström (2010), which feature rich learning dynamics and focus on amplification during crises. ${ }^{6}$ Instead of incorporating learning which creates time variation in the liquidity of a given asset, we invoke uncertainty shocks which cause demand shifts across assets with different statecontingent liquidity profiles. This allows us to derive a broad set of results across financial markets.

Bansal, Coleman, and Lundblad (2010), Greenwood, Hanson, and Stein (2012), Krishnamurthy and Vissing-Jorgensen (2012b), Gennaioli, Shleifer, and Vishny (2013), and Caballero and Farhi (2013) also study environments in which households have preferences for safe or liquid securities supplied by financial intermediaries. ${ }^{7}$ On the methodological side, these papers employ two-period frameworks that do not speak to the dynamic relation between liquidity, uncertainty, and pledgability that is the focus here. On the conceptual side, we distinguish between fully-safe (money) and near-safe (shadow money) securities and focus on the tradeoffs between them. ${ }^{8}$

The unprecedented actions of central banks in the wake of the 2008 financial crisis have sparked research interest in unconventional monetary policy and financial stability. ${ }^{9}$ We analyze these interventions from the perspective of the liquidity transformation role of the financial sector. Our model is consistent with the finding in Krishnamurthy and VissingJorgensen (2013) that central bank purchases of risky assets are more effective than purchases of long-dated government debt.

Recent empirical work has examined the cyclicality of financial sector leverage. Adrian

\footnotetext{
${ }^{6}$ Kurlat (2012) and Bigio (2013) study a related form of amplification driven by asymmetric information.

${ }^{7}$ Holmström and Tirole (1998) and Kiyotaki and Moore (2012) model the liquidity needs of the production sector by building liquidity into the production function. Our model is easily modified to take this perspective.

${ }^{8}$ Gennaioli, Shleifer, and Vishny (2013) share our interpretation of shadow banking as the creation of near-safe securities, focusing on the potential for misperceived risks that arises as a result.

${ }^{9}$ Kiyotaki and Moore (2012), Gertler and Karadi (2011), and Ashcraft, Gârleanu, and Pedersen (2011) are good examples.
} 
and Shin (2010) find that broker-dealer leverage is pro-cyclical, whereas the opposite seems to be the case for commercial banks (He, Khang, and Krishnamurthy 2010). Gorton and Metrick (2011) show that margins in repo markets increased sharply during the financial crisis. In our model, as shadow banking markets dry up in a downturn, institutions like broker-dealers that depend on them for funding are forced to de-lever. This effect is muted for money-only issuers whose funding is stable (e.g. commercial banks).

In our model as in Adrian and Boyarchenko (2012), aggregate financial sector leverage is pro-cyclical, whereas in models where the key role is played by intermediary net worth, the opposite is true. ${ }^{10}$ Consistent with the view that leverage is low in bad times, Adrian, Etula, and Muir (2011) show that exposure to a leverage growth factor carries a positive risk premium in the cross section of equities. Our results are also consistent with the evidence in Adrian, Moench, and Shin (2010) that periods of high leverage growth are followed by lower expected returns. As in the data (Frazzini and Pedersen 2010), our model produces a security market line that flattens out to the right. Our model predicts further that this "low-risk anomaly" should strengthen during periods of high uncertainty when liquidity is scarce, but we are not aware of empirical evidence along these lines.

Sunderam (2013) offers empirical support for the view that the liabilities of the shadow banking system provide monetary services. Krishnamurthy and Vissing-Jorgensen (2012a) show that the supply of government debt affects the spread between money (Treasurys) and shadow money (AAA-rated commercial paper), which is consistent with our model. Similarly, Krishnamurthy and Vissing-Jorgensen (2012b) show that government debt crowds out private money. As documented by Krishnamurthy and Vissing-Jorgensen (2012b), in our model financial crises occur when the supply of shadow money is high because it is only then that cash flow shocks have a substantial impact on asset prices.

\footnotetext{
${ }^{10}$ Leverage is typically pro-cyclical in models with VaR-type constraints and counter-cyclical volatility like Brunnermeier and Pedersen (2009).
} 


\section{Model}

We develop a model of financial intermediation built on two frictions. Households experience liquidity events characterized by a high marginal value of consumption, but their spending is constrained by their liquid holdings. This creates a precautionary demand for liquid assets but a limited liability constraint on the part of intermediaries limits their supply. Absent either friction, the economy features constant asset prices and high investment and growth.

\subsection{Technology}

Consider an economy set in continuous time $t \geq 0$. Agents are endowed with production technologies that embed a tradeoff between productivity and risk. Technology $A$ is highproductivity but risky, technology $B$ is low-productivity but safe. Let $k^{i}$ for $i=a, b$ denote the efficiency units of capital devoted to each technology and write

$$
d k_{t}^{i}=\mu\left(k_{t}^{a}+k_{t}^{b}\right)+k_{t}^{i}\left[\phi\left(\iota_{t}^{i}\right)-\delta\right] d t-k_{t}^{i} \kappa^{i}\left(d N_{t}-\lambda_{t} d t\right)
$$

where $\iota^{i}$ is the investment rate, $\mu$ is a constant level inflow of capital that does not require investment, $\phi$ is an investment adjustment cost function, $\kappa^{i}$ reflects cash flow risk, and $\delta$ is depreciation. The level inflow term $\mu\left(k_{t}^{a}+k_{t}^{b}\right)$ serves a technical purpose. ${ }^{11}$ To keep things simple, we assume this inflow accrues to the aggregate capital stock but not inside the portfolios of investors in our model. For example, it can stand in for the arrival of new workers with productivity drawn from a fixed distribution.

The rate of output is $y_{t}=\gamma^{a} k_{t}^{a}+\gamma^{b} k_{t}^{b}$, where $\gamma^{a}>\gamma^{b}$ reflects the productivity advantage of $A$ capital. Since households are risk-neutral, first-best investment favors $A$ over $B$.

The stochastic exposure of capital is driven by a Poisson jump process $N_{t}$ with timevarying perceived intensity $\lambda_{t}$ modeled in the next section. We require jumps in order to

\footnotetext{
${ }^{11}$ Specifically, this term makes the boundaries of our capital mix state variable reflecting rather than absorbing. The effect is a more gradual change in prices along the capital mix dimension. We keep $\mu$ small in calibrations.
} 
generate a wedge between the current value and the collateral value of an asset. In a crash, $d N_{t}=1$, a proportion $\kappa^{a}$ of $A$ capital and $\kappa^{b}$ of $B$ capital are destroyed. We assume $A$ capital is riskier, $\kappa^{a}>\kappa^{b}$. The crash exposures are compensated so that higher crash risk $\lambda_{t}$ does not affect expected growth (see Brunnermeier and Sannikov Brunnermeier and Sannikov (2013) for a similar formulation), and changes in $\lambda_{t}$ are pure uncertainty shocks. Once again, since households are risk-neutral, first-best capital prices are independent of $\lambda_{t}$.

We think of technology $A$ as representing new, high-potential but untested investment projects, versus the storage-like safe but less productive technology $B$. As examples, it may be useful to have in mind commercial real estate loans versus prime mortgages. ${ }^{12}$

The capital evolution dynamics (1) feature two forms of technological illiquidity: capital cannot be directly redeployed across technologies and investment is subject to adjustment costs. These generate persistence: today's investment affects tomorrow's asset mix. This will result in buildups of risky capital during prolonged booms and retrenchment at the expense of growth during downturns.

As a result of technological illiquidity, the economy's asset mix becomes a state variable. Let $\chi=k^{a} /\left(k^{a}+k^{b}\right)$ and apply Itos's Lemma using (1):

$$
\begin{aligned}
d \chi_{t}= & \mu\left(1-2 \chi_{t}\right) d t+\chi_{t}\left(1-\chi_{t}\right)\left[\phi\left(\iota_{t}^{a}\right)-\phi\left(\iota_{t}^{b}\right)+\lambda_{t}\left(\kappa^{a}-\kappa^{b}\right)\right] d t \\
& -\chi_{t}\left(1-\chi_{t}\right)\left[\frac{\kappa^{a}-\kappa^{b}}{\chi_{t}\left(1-\kappa^{a}\right)+\left(1-\chi_{t}\right)\left(1-\kappa^{b}\right)}\right] d N_{t} .
\end{aligned}
$$

Absent a crash, the risky asset share $\chi$ drifts according to relative investment in the two technologies (adjusted by the level-inflow and crash-compensating terms). During a crash, the risky asset share falls as more of the risky capital is wiped out. In other words, crashes shift the economy's capital stock towards safety. This produces a dampening effect: uncertainty shocks absent a crash have a stronger impact on asset prices. ${ }^{13}$

\footnotetext{
${ }^{12}$ To motivate these examples, note that (1) commercial real estate is strongly pro-cyclical; (2) commercial real estate loans enjoy no government guarantees; and (3) they offer a higher return on investment. From an ex ante perspective and for the same reasons, subprime loans can also be interpreted as type- $A$ capital, though of course ex post their "productivity" has been called into question.

${ }^{13}$ There are several ways to remove the dampening effect: (1) introduce a capital composition shock that
} 


\subsection{Uncertainty}

We interpret the crash intensity $\lambda_{t}$ as the outcome of a filtering problem. Suppose that the jump process $N_{t}$ has a true, latent intensity $\tilde{\lambda}_{t}$ that follows a two-state Markov chain, $\tilde{\lambda} \in\left\{\lambda_{L}, \lambda_{H}\right\}$, with transition intensities $q^{L}$ and $q^{H}$ from the low and high states, respectively.

Households learn about $\tilde{\lambda}$ from the occurrence of crashes as well as from an additional diffusive signal with precision $1 / \sigma_{e}$. The diffusive signal captures the arrival of uncertaintyrelevant news. ${ }^{14}$ In Appendix A, we show how to compute the filtered process $\lambda_{t}=E_{t}\left[\tilde{\lambda}_{t}\right]$ :

$$
\frac{d \lambda_{t}}{\left(\lambda^{H}-\lambda_{t}\right)\left(\lambda_{t}-\lambda^{L}\right)}=\left(-\frac{q^{H}}{\lambda^{H}-\lambda_{t}}+\frac{q^{L}}{\lambda_{t}-\lambda^{L}}-1\right) d t+\frac{1}{\sigma_{e}} d B_{t}+\frac{1}{\lambda_{t}} d N_{t}
$$

We note three properties of the filtered crash intensity. First, it tends to drift down, so crashes are less likely following a prolonged quiet period. This leads to buildups of leverage and asset risk (the volatility paradox in the language of Brunnermeier and Sannikov (2013)). Second, crash realizations cause $\lambda_{t}$ to jump up. ${ }^{15}$ As a result, crashes are followed by persistent deleveraging, a shift towards safe capital, and low growth. Third, $\lambda_{t}$ jumps most from low levels (in particular, from the neighborhood of $\sqrt{\lambda^{L} \lambda^{H}}<\frac{1}{2}\left(\lambda^{L}+\lambda^{H}\right)$ ). It follows that crashes after prolonged booms have the strongest effects on funding costs, the optimal mix of securities, asset prices, and investment. ${ }^{16}$

converts some fraction of the safe capital into risky capital when a crash hits; and (2) a crash need not destroy any capital in the aggregate, it is enough that it destroy some units of capital while benefiting others (a dispersion shock) as long as investors cannot hold fully diversified portfolios. We pursue the latter approach in Sections 3.4 (Flight to quality) and 4.3 (Operation Twist).

${ }^{14}$ The failure of the two Bear Sterns hedge funds in the summer of 2007 are an illustration of the type of news we have in mind.

${ }^{15}$ Consistent with this underlying dynamic, Reinhart and Reinhart (2010) find that over half of all economies that suffer a financial crisis experience follow-ups.

${ }^{16}$ An alternative way to model uncertainty shocks would be to vary crash size instead of frequency. In this case, collateral values would also fall following a rise in uncertainty, not endogenously via prices, but directly via cash-flow risk. We choose not to pursue this route for three reasons. First, learning gives us a natural connection between the occurrence of a crash and crash intensity. Second, by making capital scarcer following a crash, a higher crash size would disproportionately reduce the issuance of fully-safe securities instead of near-safe securities, contrary to the evidence (e.g. Gorton and Metrick 2011). Third, we are particularly interested in endogenous risk. 


\subsection{Securities and asset markets}

There are two aggregate shocks in our economy and three financial securities that span them. We call these money, shadow money, and equity in order to convey their risk and liquidity profiles. We will show that the optimal provision of liquidity generally requires all three securities, and that the three are indeed sufficient.

We write the innovations to the return processes of money, shadow money, and equity as

$$
\begin{aligned}
d r_{m, t} & =\mu_{m, t} d t \\
d r_{s, t} & =\mu_{s, t} d t-\kappa_{s, t}\left(d N_{t}-\lambda_{t} d t\right) \\
d r_{e, t} & =\mu_{e, t} d t-\sigma_{e, t} d B_{t}-\kappa_{e, t}\left(d N_{t}-\lambda_{t} d t\right)
\end{aligned}
$$

respectively. All drifts and loadings are determined endogenously. Money is fully safe. Shadow money is safe at all times except in a crash when it takes a loss. Equity absorbs all normal-times risk and the remaining crash risk.

Given risk neutrality, volatility is only relevant insofar as it relates to liquidity. Guided by the information-sensitivity literature (Gorton and Pennacchi 1990), we call a security liquid if the sensitivity of its expected return with respect to private information does not exceed a fixed upper bound that we think of as the cost of information. Formally,

Definition 1. An asset with return process $d S_{t}$ is liquid if and only if

$$
\frac{1}{d t}\left(\frac{E_{t}\left[d S_{t} \mid \tilde{\lambda}_{t}\right]-E_{t}\left[d S_{t} \mid \lambda_{t}\right]}{\tilde{\lambda}_{t}-\lambda_{t}}\right) \leq \bar{\kappa}
$$

where $\bar{\kappa}<1$ is a fixed constant.

In Appendix B, we derive microfoundations for this definition by examining the information acquisition problem of an arbitrageur. Intuitively, a high sensitivity to private information gives agents - households and intermediaries alike - a strong incentive to become 
privately informed. If this incentive exceeds the cost of information, an adverse selection problem can arise in either the secondary or primary securities markets. For example, an informed intermediary could time its securities issuance to earn abnormal profits, or an informed household could feign a liquidity event in an attempt to offload overpriced securities. Adverse selection would limit market liquidity, making it difficult to quickly exit a position during a genuine liquidity event.

It is clear given our definition that money is liquid. For shadow money to be liquid, substituting (5) into (7), it must be the case that

$$
\kappa_{s, t} \leq \bar{\kappa}
$$

To be liquid ex ante, shadow money must not suffer too large a loss ex post. We assume that shadow money ceases to be liquid ex post in the event of a loss. ${ }^{17}$ For example, recovery may be prolonged due to a "failure to deliver", extended legal proceedings, or the defaulted security may be subject to greater adverse selection.

Finally, there is also a frictionless market for existing capital, with price dynamics

$$
\frac{d \pi_{t}^{i}}{\pi_{t}^{i}}=\mu_{\pi, t}^{i} d t-\sigma_{\pi, t}^{i} d B_{t}-\kappa_{\pi, t}^{i}\left(d N_{t}-\lambda_{t} d t\right)
$$

for $i=a, b$. We solve for prices in equilibrium, and they determine investment and growth.

\footnotetext{
${ }^{17}$ This assumption drives a wedge between the amount of collateral firms must use to back shadow money and the amount of liquidity households derive from it. If instead the recovered amount remains liquid, the leverage advantage of shadow money over money always exceeds the relative valuations of households. This means that money is not produced except in states where equity is not required in the first place.
} 


\subsection{Households}

The economy is populated by households with risk-neutral preferences who are subject to liquidity shocks as in Diamond and Dybvig (1983). Specifically, households maximize

$$
V_{t}=\max E_{t}\left[\int_{t}^{\infty} e^{-\rho(u-t)} W_{u}\left(c_{u} d u+\psi C_{u} d N_{u}^{h}\right)\right]
$$

where $N_{t}^{h}$ is a Poisson jump process with constant intensity $h$ that is uncorrelated with $N_{t}$. A realization $d N_{t}^{h}=1$ signifies the onset of a liquidity event, defined as an opportunity to consume a fraction of wealth $C_{t}$ up to a limit $C_{t}^{*}$ at a high marginal value $\psi>1$. To generate a concave demand for liquidity, we assume $C_{t}^{*}$ is random, specifically i.i.d. exponential with mean $1 / \eta$. For example, a household may have to make a large payment of unknown size.

Liquidity-event consumption is also constrained by the household's liquid holdings $l_{t},{ }^{18}$

$$
C_{t} \leq \min \left\{C_{t}^{*}, l_{t}\right\}
$$

A household experiencing a liquidity event must quickly sell off a substantial part of its portfolio. As emphasized by Gorton and Pennacchi (1990), only certain securities, in particular those with a low sensitivity to private information, can be sold quickly and in large quantities without incurring the costs associated with price impact.

Recall that shadow money ceases to be liquid if it suffers a loss. We assume that a household in a liquidity event experiences such a loss with probability $1-e^{-\tau \lambda_{t}}$. Letting $m_{t}$ and $s_{t}$ be the weights of money and shadow money in the household's portfolio, its liquid assets are $l_{t}=m_{t}+s_{t}$ absent a loss (probability $e^{-\tau \lambda_{t}}$ ) and $l_{t}=m_{t}$ given a loss (probability $\left.1-e^{-\tau \lambda_{t}}\right)$. A rise in uncertainty $\lambda_{t}$ thus makes shadow money less attractive.

We have linked the probability of a loss during a liquidity event to the probability of an

\footnotetext{
${ }^{18}$ We are ruling out a market for individual liquidity insurance. Households must self-insure by amassing a precautionary buffer of liquid assets. A form of liquidity insurance can be introduced via collateral rehypothecation.
} 
aggregate crash. To motivate this link, we interpret a liquidity event as in fact lasting $\tau$ periods, with a burst of consumption coming at the end. The probability that a crash occurs during $\tau$ periods would indeed be $1-e^{-\tau \lambda_{t}}$ if $\lambda_{t}$ were to remain constant. Since in reality it does not remain constant, our formulation represents a simplification that preserves the intuition of a positive-duration liquidity event while maintaining tractability. This allows us to study the interaction between liquidity demand and uncertainty.

\subsection{Intermediaries}

Intermediaries buy capital, set investment, and issue securities to maximize profits. Although we have combined the investment and liquidity provision functions under one roof, these can easily be separated as investment here is static. We think of the intermediaries as financial institutions since their key role is the tranching of assets.

In contrast to the literature, in this model intermediaries can issue and repurchase equity without any frictions. To formulate the intermediary's maximization problem, we distinguish between existing and new equity. Specifically, the intermediary maximizes the value of existing equity:

$$
\rho V_{t} d t=\max _{k_{t}^{a}, k_{t}^{b}, \iota_{t}^{a}, \iota_{t}^{b}, m_{t}, s_{t}}\left[\left(\gamma^{a}-\iota_{t}^{a}\right) k_{t}^{a}+\left(\gamma^{b}-\iota_{t}^{b}\right) k_{t}^{b}\right] d t+E_{t}\left[d V_{t}\right]
$$

where $k_{t}^{a}$ and $k_{t}^{b}$ are units of capital, $\iota_{t}^{a}$, and $\iota_{t}^{b}$ are investment rates, and $m_{t}$ and $s_{t}$ are the ratios of the intermediary's money and shadow money liabilities to assets. Neither can be negative, $m_{t}, s_{t} \geq 0$.

The value of purchased capital $A_{t}=\pi_{t}^{a} k_{t}^{a}+\pi_{t}^{b} k_{t}^{b}$ pins down the size of the intermediary's balance sheet. Any discrepancy between $A_{t}$ and the intermediary's money, shadow-money, and existing equity must be made up with new equity, which is compensated at the equilib- 
rium rate of return. The evolution of existing equity $V_{t}$ is given by

$$
d V_{t}=d A_{t}-A_{t}\left(m_{t} d r_{m, t}+s_{t} d r_{s, t}\right)-\left[A_{t}-A_{t}\left(m_{t}+s_{t}\right)-V_{t}\right] d r_{e, t} .
$$

The change in the value of existing equity is equal to the change in the value of total assets minus the payouts to money, shadow money, and newly-issued equity.

The intermediary faces a limited liability constraint. Specifically, new equity cannot be used to pay for previously incurred losses; assets must be sufficient to cover existing liabilities after any write-offs. This prevents firms from issuing unlimited amounts of money and shadow money backed by ex post equity infusions. Limited liability can be microfounded with lack of commitment: an infusion into an insolvent firm is not optimal ex post as there are no reputation or distress costs.

Limited liability must hold state by state, namely both during normal times and in a crash. Let $\kappa_{A, t}$ be the fraction of asset value lost in a crash so that $1-\kappa_{A, t}$ is the asset collateral value. We have

$$
\begin{aligned}
& m_{t}+s_{t} \leq 1 \\
& m_{t}+s_{t} \leq 1-\kappa_{A, t}+s_{t} \kappa_{s, t} .
\end{aligned}
$$

By writing (14) as a weak inequality, we are implicitly allowing equity infusions on the order of the normal-times shock $d B_{t} \cdot{ }^{19}$ Equation (15) shows that one dollar of collateral can back one dollar of money or $1 /\left(1-\kappa_{s, t}\right)>1$ dollars of shadow money.

Applying Ito's Lemma to $A_{t}$,

$$
1-\kappa_{A, t}=\frac{\pi_{t}^{a} k_{t}^{a}}{\pi_{t}^{a} k_{t}^{a}+\pi_{t}^{b} k_{t}^{b}}\left(1-\kappa_{\pi, t}^{a}\right)\left(1-\kappa^{a}\right)+\frac{\pi_{t}^{b} k_{t}^{b}}{\pi_{t}^{a} k_{t}^{a}+\pi_{t}^{b} k_{t}^{b}}\left(1-\kappa_{\pi, t}^{b}\right)\left(1-\kappa^{b}\right) .
$$

\footnotetext{
${ }^{19}$ This assumption simply means that in the region of the state-space where all crash losses are optimally covered by shadow money, equity can be reduced to zero instead of just to near-zero.
} 
Collateral values are driven by cash-flow risk which changes with the asset mix, and by price risk, which arises endogenously. Notice that even a cash-flow safe asset (e.g. $\left.\kappa^{b}=0\right)$ cannot directly back money as fluctuations in household demand for liquidity introduce volatility into its price $\left(\sigma_{\pi, t}^{b}, \kappa_{\pi, t}^{b}>0\right)$. This happens because the liquidity services it provides become an important component of its value.

\subsection{The demand for liquidity}

Households use liquid securities to self-insure against liquidity events, whose random size generates a concave demand for overall liquidity. As crashes become more likely, households seek securities that remain liquid in all states. Demand for money rises and demand for shadow money falls, a flight to quality effect.

The household optimization problem can be formulated as

$$
\rho V_{t} d t=\max _{c_{t}, C_{t}, m_{t}, s_{t}} W_{t}\left(c_{t} d t+\psi E_{t}\left[C_{t} d N_{t}^{h}\right]\right)+E_{t}\left[d V_{t}\right]
$$

subject to the standard budget constraint and the liquidity constraint

$$
C_{t} \leq \min \left\{C_{t}^{*}, l_{t}\right\}
$$

Risk neutrality imposes $V_{t}=W_{t}$. Non-liquidity consumption $c_{t}$ is supplied elastically. ${ }^{20}$

Since $\psi>1$, the liquidity constraint always binds, $C_{t}=\min \left\{C_{t}^{*}, l_{t}\right\}$. Households consume as much as possible when a high-value opportunity arises.

Evaluating expectations under the exponential distribution, the portfolio optimality con-

\footnotetext{
${ }^{20}$ This is a feature of the assumption that households are risk-neutral and can consume negative amounts. Note that even though liquidity-event consumption is lumpy, normal-times consumption is of order $d t$ since normal-times marginal utility is constant.
} 
ditions pin down spreads in the securities markets:

$$
\begin{aligned}
\mu_{e, t}-\mu_{m, t} & =h(\psi-1)\left[e^{-\tau \lambda_{t}} e^{-\eta\left(m_{t}+s_{t}\right)}+\left(1-e^{-\tau \lambda_{t}}\right) e^{-\eta m_{t}}\right] \\
\mu_{s, t}-\mu_{m, t} & =h(\psi-1)\left(1-e^{-\tau \lambda_{t}}\right) e^{-\eta m_{t}}
\end{aligned}
$$

The equity premium equals the marginal benefit of liquidity in all states and shadow money premium, which we call the safety spread, equals the marginal benefit of liquidity in the crash state. Clearly, both money and shadow money trade at a premium over equity, and money trades at a premium over shadow money. All else equal, a rise in uncertainty $\lambda_{t}$ increases the safety spread. In the next section, we will see that intermediaries respond by issuing more money and less shadow money, which requires deleveraging.

Substituting the optimality conditions (19) and (20) into the HJB equation and rearranging gives the aggregate cost of capital (the return on savings):

$$
\rho-\frac{h}{\eta}(\psi-1)\left(1-\left[e^{-\tau \lambda_{t}} e^{-\eta\left(m_{t}+s_{t}\right)}+\left(1-e^{-\tau \lambda_{t}}\right) e^{-\eta m_{t}}\right]\right)
$$

The cost of capital is decreasing in overall liquidity since greater liquidity encourages saving by raising the opportunity for consumption during a liquidity event when it is most valuable.

\subsection{The supply of liquidity}

In this section, we characterize the liabilities side of an intermediary's maximization problem.

In Appendix $\mathrm{C}$, we show how to state the liabilities problem more generally as a statecontingent liquidity provision problem. Here, we provide a result stating that the solution to this problem can be implemented with money, shadow money, and equity. This amounts to a proof that our assumed securities structure is without loss of generality. Moreover, it also allows us to show that in equilibrium shadow money is collateralized just enough to be liquid, and that equity is illiquid and uncollateralized. Formally, 
Proposition 1. The intermediary's optimal capital structure policy is characterized by

i. $m_{t}=0$ and $s_{t}=\left(1-\kappa_{A, t}\right) /(1-\bar{\kappa})$ if $\kappa_{A, t} \geq \bar{\kappa}$ and $\kappa_{A, t}>1-\frac{1-\bar{\kappa}}{\eta} \log \left(\frac{\bar{\kappa}}{1-\bar{\kappa}} \frac{e^{-\tau \lambda_{t}}}{1-e^{-\tau \lambda_{t}}}\right)$;

ii. $m_{t}=1-\kappa_{A, t}$ and $s_{t}=0$ if $\lambda_{t}>-\frac{1}{\tau} \log (1-\bar{\kappa})$;

iii. $m_{t}=1-\kappa_{A, t} / \bar{\kappa}$ and $s_{t}=\kappa_{A, t} / \bar{\kappa}$ if $\kappa_{A, t} \leq \bar{\kappa}$ and $\kappa_{A, t}<\frac{\bar{\kappa}}{\eta} \log \left(\frac{\bar{\kappa}}{1-\bar{\kappa}} \frac{e^{-\tau \lambda_{t}}}{1-e^{-\tau \lambda_{t}}}\right)$; and

iv. $m_{t}=\left(1-\kappa_{A, t}\right)-\frac{1-\bar{\kappa}}{\eta} \log \left(\frac{\bar{\kappa}}{1-\bar{\kappa}} \frac{e^{-\tau \lambda_{t}}}{1-e^{-\tau \lambda_{t}}}\right)$ and $s_{t}=\frac{1}{\eta} \log \left(\frac{\bar{\kappa}}{1-\bar{\kappa}} \frac{e^{-\tau \lambda_{t}}}{1-e^{-\tau \lambda_{t}}}\right)$ otherwise.

The intermediary optimally sets $\kappa_{r, t}=\bar{\kappa}$ so shadow money is liquid and $\kappa_{e, t}=1$ so equity is illiquid. Absent money and shadow money, liquidity provision is suboptimal in all cases. Absent only shadow money, liquidity provision is suboptimal in all cases except (ii).

The proof is provided in Appendix C. Case $(i)$ occurs when uncertainty is low enough so that crash-proof liquidity is not worth its high collateral cost. In this case all collateral is pledged to deliver normal-times liquidity and this is implemented with shadow money. By contrast, under case $(i i)$ high uncertainty raises demand for crash-proof liquidity to the point where money uses up all available collateral and no shadow money is issued. Under case (iii), low asset risk allows intermediaries to deliver normal-times liquidity equal to the full value of their assets so no equity is needed. Finally, in the interior case $(i v)$ the marginal rate of substitution between normal-times and crash-proof liquidity is equated with the leverage advantage of shadow money over money.

Intermediaries keep shadow money liquid in order to take advantage of the liquidity premium that households are willing to pay. They pledge the minimal amount of necessary collateral in order to maximize liquidity provision.

Equity is an inefficient instrument for providing liquidity. Normal-times risk, $\sigma_{e, t}>0$, means that to be liquid equity would use up more collateral than shadow money (applied to equity, (7) becomes $\sigma_{e, t}+\kappa_{e, t} \leq \bar{\kappa}$ ). Once equity is illiquid, it is optimal to set $\kappa_{e, t}$ to free up collateral for liquid instruments. Thus, equity is always wiped out in a crash. 
Although there are no differences in expertise or preferences between households and intermediaries, holding capital directly is not efficient in this economy. We see this because in all regions of the state-space, at least two of the three available securities are required for optimal liquidity provision. Shadow money is unnecessary only in the highest-uncertainty states. Tranching is thus always efficient, and this is how intermediaries add value.

In sum, intermediaries trade off the leverage advantage of shadow money against the funding advantage of money. Every dollar of collateral can back one dollar of money or $1 /(1-\bar{\kappa})$ dollars of shadow money. When uncertainty rises, the marginal rate of substitution between normal-times liquidity and crash-proof liquidity falls below the leverage advantage of shadow money, and intermediaries substitute money and equity for shadow money. This leads to deleveraging and a shutdown of shadow banking markets.

\subsection{Asset prices and investment}

On the asset side of the balance sheet, intermediaries purchase capital and set investment. Let $A_{t} \theta_{t}^{c}$ and $A_{t} \theta_{t}^{n}$ be the LaGrange multipliers on the crash-state and normal-times limited liability constraints (14) and (15). Explicit expressions are provided in Appendix C. Each additional dollar of assets relaxes the normal-times constraint by one dollar and the crashstate constraint by $1-\kappa_{A, t}$ dollars. From (12) and (13), after applying Ito's Lemma to $A_{t}=\pi_{t}^{a} k_{t}^{a}+\pi_{t}^{b} k_{t}^{b}$, we get that the optimal investment policy sets Tobin's $q$ to one:

$$
1=\pi_{t}^{i} \phi^{\prime}\left(\iota_{t}^{i}\right)
$$

for $i=a, b$. Higher asset prices lead to higher investment and growth. Prices themselves are determined in the market for capital, where optimality requires

$$
\mu_{e, t}-\theta_{t}^{c}\left(1-\kappa^{i}\right)\left(1-\kappa_{\pi, t}^{i}\right)-\theta_{t}^{n}=\frac{\gamma^{i}-\iota_{t}^{i}}{\pi_{t}^{i}}+\left[\mu_{\pi, t}^{i}+\phi\left(\iota_{t}^{i}\right)-\delta+\kappa^{i} \kappa_{\pi, t}^{i} \lambda_{t}\right]
$$


for $i=a, b$. The left side is the discount rate and the right side is the expected return of each asset. The return has a cash flow component which is higher for $A$ capital since $\gamma^{a}>\gamma^{b}$, and an expected appreciation component that takes into account price growth, physical growth, and depreciation (there is also an adjustment coming from the crash-compensation term).

Discount rates vary across the two assets as a result of their differential ability to supply liquidity. Both assets are funded at a discount from the cost of equity, and this discount

depends on their collateral values. Since type- $A$ capital is riskier, $\kappa^{a}>\kappa^{b}$, and since collateral is generally scarce, $\theta_{t}^{c}>0$, its discount rate tends to be higher than that of $B$ capital. Although it has higher cash flows, type- $A$ capital can have a lower price than type- $B$ capital if liquidity is sufficiently scarce. As liquidity becomes more abundant, not only does the overall cost of capital fall, but the wedge in discount rates between the two types of capital shrinks. This means that greater liquidity provision raises investment overall, and investment in $A$ capital in particular.

\section{Results}

In this section, we present the results of the model, focusing on its macroeconomic dynamics and financial markets effects. We solve the model by characterizing PDEs in $\pi_{t}^{a}=\pi^{a}\left(\lambda_{t}, \chi_{t}\right)$ and $\pi_{t}^{b}=\pi^{b}\left(\lambda_{t}, \chi_{t}\right)$, which we then solve numerically using projection methods. Appendix D provides details.

We follow Brunnermeier and Sannikov (2013) and pick an investment cost function that implies quadratic adjustment costs, $\phi\left(\iota_{t}\right)=\frac{1}{\varphi}\left(\sqrt{1+2 \varphi \iota_{t}}-1\right)$. Our benchmark parameter values are available in Table I. We view these as an illustration rather than a calibration.

Table I about here. 


\subsection{Macroeconomic effects}

Figure 1 plots key macroeconomic quantities in our benchmark economy against the level of uncertainty $\lambda$ at three different levels of the risky asset share $\chi$. The top two panels show the prices of the high-productivity low-collateral $A$ capital and the low-productivity highcollateral $B$ capital. The price of $A$ is generally higher, reflecting its greater productivity. However, it declines steeply with $\lambda$ and gradually with $\chi$. By contrast, the price of $B$ is increasing in $\chi$ and flat in $\lambda$ except when $\chi$ is high where it is at first increasing and then decreasing in $\lambda$. The price of $B$ can even exceed the price of $A$ when uncertainty $\lambda$ and asset risk $\chi$ are high.

Figure 1 about here.

The middle panels of Figure 1 plot the supply of money and shadow money, which help to understand these price effects. When uncertainty is low, households are willing to hold shadow money to meet their liquidity needs. Intermediaries are similarly eager to supply shadow money as it allows them to lever up the collateral value of their assets to create more liquidity and lower their funding costs. As a result, shadow money displaces money at low levels of uncertainty and especially when the supply of collateral is low ( $\chi$ is high). Shadow banking lowers the funding cost of the productive asset, boosting its price.

The bottom left panel of Figure 1 plots the overall supply of liquidity measured as the net present value of liquidity-event consumption. Shadow banking allows for a high level of liquidity even when the capital mix is risky as long as uncertainty is low. It is in this region that the financial sector is engaging in liquidity transformation and not simply liquidity provision.

Output growth in the bottom-right panel of Figure 1 is also highest when uncertainty is low and the share of the productive $A$ capital is high. By increasing the supply of liquidity for a given amount of collateral, shadow banking lowers discount rates and pushes up prices, investment, and growth. Note that a highly liquid economy is not coincident with a fast- 
growing one: the supply of liquidity can be very high when asset risk is low but the low level of the productive asset $A$ actually causes the economy to shrink. In other words, it is shadow banking that enables an economic boom via liquidity transformation.

A rise in uncertainty sets off a contraction in liquidity transformation and ultimately a recession. Household demand shifts abruptly from shadow money to money as only money provides liquidity in a crash. Intermediaries cater to this demand by adjusting their liabilities. The shadow banking sector effectively shuts down within a narrow range of uncertainty. In the financial crisis of 2007-2008, the market for asset-backed commercial paper suffered a similarly abrupt collapse.

Issuing more money forces intermediaries to raise equity. ${ }^{21}$ The result is less liquidity provision and higher discount rates. The price of $A$ capital falls sharply while $B$ capital becomes more valuable as the liquidity shortage increases the premium for collateral. This effect is strongest when collateral is scarce to begin with ( $\chi$ is high). The reversal of investment from productivity to safety can be interpreted as cash hoarding.

Importantly, it is neither a lack of intermediary capital nor a lack of demand for credit that causes intermediaries to stop investing in productive capital when uncertainty rises. In fact, equity is higher than ever while the investment opportunity set is unchanged. It is the low level of liquidity provision resulting from the contraction of shadow banking that produces the downturn.

\subsection{Persistence}

Our model generates persistence so booms and busts each last a while. First, uncertainty is persistent due to learning: it takes a few years absent a crash for $\lambda$ to come down, and if there are aftershocks, it takes even longer. Second, the capital mix $\chi$ is slow-moving due to technological illiquidity. These two sources of persistence interact so that a rise in uncertainty

\footnotetext{
${ }^{21}$ As a result aggregate financial sector equity issuances are strongly counter-cyclical in the model.Adrian and Shin (2010) shows evidence consistent with this pattern, but we are not aware of any paper that has investigated financial sector net equity issuance directly in the data.
} 
throws the economy off its target capital mix, setting it on a long path to recovery.

To illustrate the persistence of our model, Figure 2 plots impulse response functions for the state variables $\lambda$ and $\chi$. The top two panels focus on $\lambda$ starting from a low level on the left and a high level on the right. The gray shading represents a contour plot of the conditional density of $\lambda$, which is calculated by solving the forward Kolmogorov equation in Appendix E. From the solid red lines, which represent conditional means, we see that $\lambda$ is highly persistent. From the shaded densities we see that this persistence is due to the combination of a downward drift that pulls much of the mass down together with occasional jumps that pull chunks of it back up.

Figure 2 about here.

The bottom panels of Figure 2 plot the conditional means of the risky asset share $\chi$ starting from a low, medium, or high level under each of the two $\lambda$ scenarios. On the left, where $\lambda$ is low, $\chi$ is increasing over time except when it is very high to begin with. Low uncertainty promotes shadow banking which raises the price of the risky asset and stimulates investment. On the right, where $\lambda$ is high, $\chi$ drifts down except when it is very low at the start. When uncertainty is high, households are unwilling to hold shadow money, which makes it costly to fund investment in the risky but productive asset $A$. At the same time, demand for collateral causes investment in the safe but unproductive asset to pick up, causing $\chi$ to fall over time.

Overall, Figure 2 illustrates the interplay between the model's credit and investment cycles. At low uncertainty, the economy drifts toward a productive but risky capital mix, whereas at high uncertainty it tends toward safety.

\subsection{Collateral runs}

Collateral runs are episodes during which liquidity creation requires progressively greater amounts of collateral, which is equivalent to a rise in haircuts. To be concrete, an asset $i$ 
with collateral value $1-\kappa$ has a haircut of $\kappa$. In our model haircuts have an exogenous cash flow component $\kappa^{i}$ and an endogenous price component $\kappa_{\pi}^{i}$ : $1-\kappa=\left(1-\kappa^{i}\right)\left(1-\kappa_{\pi}^{i}\right)$. A collateral run occurs when $\kappa_{\pi}^{i}=1-\pi_{+}^{i} / \pi^{i}$ rises even as $\pi^{i}$ falls (pluses denote after-crash prices). This requires that higher discount rates today foreshadow even higher discount rates in the event of a crash, causing a downward price spiral. In sum, a collateral run occurs when the rise in discount rates accelerates in uncertainty as it does when uncertainty is low. ${ }^{22}$

Figure 3 about here.

To demonstrate the effects of collateral runs, Figure 3 compares haircuts, capital structures, funding costs, and asset prices in economies with and without a shadow banking sector. $^{23}$ We fix $\chi=0.5$ and look across $\lambda$.

In a shadow-banking economy near the peak of the credit cycle (low $\lambda$ ), an uptick in uncertainty leads to a rise in both haircuts and discount rates. Higher haircuts raise funding costs by forcing a shift toward more expensive funding. As a result, prices fall further, which represents a collateral run.

In a collateral run, money yields fall while shadow money yields rise sharply. Since the economy is near its peak, shadow banking activity is very high and so overall discount rates rise. The risky $A$ capital suffers the greatest price decline as its funding is most fragile. Although the amplification of collateral runs causes discount rates to spike above their levels in the no-shadow-banking economy, the price of $A$ capital is always higher with shadow banking than without because prices capitalize the lower funding costs in a shadow-bankingdriven boom. The possibility of future credit booms leads to less severe downturns.

When $\lambda$ is high and the economy is near bottom, a fall in uncertainty leads to a rise in haircuts. Thus, as an economy recovers its exposure to uncertainty initially increases, which

\footnotetext{
${ }^{22}$ Note that a collateral run is distinct from a classic bank run. Agents in our model demand bigger haircuts when financial conditions become more sensitive to uncertainty shocks. They do not face a first-come-firstserved constraint as in Diamond and Dybvig (1983). A bank run could arise in our model if collateral is rehypothecated among investors. We hope to explore this possibility in future research.

${ }^{23}$ We implement a no-shadow banking economy with $\bar{\kappa}=0$ which removes the leverage advantage of shadow money.
} 
slows down the recovery of prices and hence investment.

\subsection{Flight to quality}

Our model generates flight to quality, a rise in the prices of safe assets even as overall prices fall. A rise in uncertainty triggers a demand shift from shadow money to money. This causes the spread between shadow money and money to widen. As intermediaries struggle to absorb the excess demand for money, the premium for good collateral rises, causing the safe $B$ capital to appreciate relative to the risky $A$ capital. When these relative price changes dominate the overall rise in discount rates, the yield of money falls and the price of $B$ capital rises, which we call flight to quality in the securities and asset markets.

Our benchmark parametrization produces modest flight to quality (see Figure 1). Intuitively, flight to quality is the result of a shortage of collateral. In our benchmark model however, crashes actually increase the relative supply of collateral as a higher proportion of the safe $B$ capital survives unscathed. In this section, we modify the model to remove this dampening effect.

Specifically, we replace the aggregate cash flow shock with a dispersion shock. Let $k_{i, t}^{a}$ and $k_{i, t}^{b}$ be the capital holdings of intermediary $i$ and modify equation (1):

$$
\left.d k_{i, t}^{a}=k_{i, t}^{a}\left[\phi\left(\iota_{i, t}^{a}\right)-\delta\right] d t-k_{i, t}^{a} \kappa_{i, t}^{a}\left(d N_{t}-\lambda_{t} d t\right)\right]
$$

where $\kappa_{i, t}^{a}= \pm \kappa^{a}$ with probability $1 / 2$ each and $\kappa_{i, t}^{b}=0$. In addition to the dispersion shock, we have simplified our benchmark specification by setting $\mu=0$, which further increases the scarcity of collateral at high levels of $\chi$. We also increase $\eta$ slightly to 2.8 , which reduces the elasticity of substitution between money and shadow money. ${ }^{24}$

The dispersion shock makes $A$ capital risky for an individual intermediary but safe in the aggregate. This keeps pledgability low but eliminates aggregate cash flow risk, highlighting

\footnotetext{
${ }^{24}$ The modified model is solved easily by simply altering the dynamics of $\chi$ in $(2)$ to $d \chi_{t}=$ $\chi_{t}\left(1-\chi_{t}\right)\left[\phi\left(\iota_{t}^{a}\right)-\phi\left(\iota_{t}^{b}\right)\right] d t$, while keeping the pricing PDE (23) unchanged.
} 
the fact that our model is about collateral rather than risk. ${ }^{25}$

Figure 4 about here.

Figure 4 shows that the model with a dispersion shock produces strong flight to quality effects in securities markets. When uncertainty $\lambda$ rises, the yield on money falls and the spread between shadow money and money (the safety spread) opens up. The effect is strongest when the capital mix is risky $(\chi=0.9)$ so that intermediaries cannot fully absorb the excess demand for money. In this case overall liquidity falls, which causes discount rates to rise as reflected in the equity premium. These dynamics resemble developments in U.S. markets after July 2007.

Figure 4 also shows strong flight to quality effects in asset markets. In the bottom right panel, the price of $B$ capital rises the most in a crash when the economy is near the peak of the credit cycle; that is when uncertainty is low, liquidity transformation is high, and the capital mix is risky $(\chi=0.9)$. U.S. long-term bonds similarly appreciated as the financial crisis unfolded in 2007-2008. Once uncertainty rises sufficiently (or the capital mix becomes safe enough) so that shadow banking shuts down, flight to quality disappears. Thus, flight to quality results from the acute shortage of collateral that occurs when uncertainty rises suddenly after a shadow banking boom.

Our model's learning dynamics tie together normal-times $(d B)$ and crash $(d N)$ flight to quality (both raise $\lambda$ ). The two, however, are conceptually distinct as normal-times shocks are borne entirely by equity whereas crashes affect pledgability and the supply of liquidity. In our model only crash-driven flight to quality is important ex ante because equity markets are frictionless. ${ }^{26}$ This observation suggests that differences in the pricing of instruments that act as normal-times versus crash-risk hedges can be used to assess the importance of

\footnotetext{
${ }^{25}$ We are implicitly assuming that intermediaries cannot diversify the dispersion shock. As a possible example, it may be difficult to distinguish ex ante which assets are likely to co-move in the rare event of a crash, (e.g. mortgages in Miami and Las Vegas). Alternatively, individual intermediaries might develop special expertise in particular markets. Note that flight to quality does not require the dispersion shock.

${ }^{26}$ We explore the ex ante effects of flight to quality in Sections 4.3 (Operation Twist) and 4.5 (Volcker rule).
} 
equity- versus collateral-based frictions.

\section{Policy interventions}

In the aftermath of the 2008 financial crisis central banks around the world and the U.S. Federal Reserve in particular have resorted to a wide variety of interventions broadly referred to as unconventional monetary policy. We use our model to analyze the asset pricing implications of two of these interventions, the Large Scale Asset Purchase (LSAP) program of 2008-2010 and the Maturity Extension Program also known as "Operation Twist" of 20112012. Under LSAP, the FED purchased large amounts of mortgage-backed securities in an effort to support their prices. ${ }^{27}$ Under Operation Twist, the FED purchased long-dated Treasurys and sold short-dated ones with the stated goal of reducing long-term interest rates. $^{28}$

Alongside central banks, regulators have entertained a broad range of proposals and implemented a subset of them. We consider two of these: the so-called "Volcker rule" which seeks to separate commercial banking and proprietary trading, and stricter capital requirements as have been adopted by the Basel III committee. We discuss our interpretation of these policies within the context of our model, and we explore their impact on liquidity provision and the broader economy.

\footnotetext{
${ }^{27}$ The press release announcing the program reads, "Spreads of rates on GSE debt and on GSE-guaranteed mortgages have widened appreciably of late. This action is being taken to reduce the cost and increase the availability of credit for the purchase of houses, which in turn should support housing markets and foster improved conditions in financial markets more generally" (Federal Open Market Committee 2008).

${ }^{28}$ The program's announcement following the September 2011 FOMC meeting reads, "The Committee intends to purchase, by the end of June 2012, $\$ 400$ billion of Treasury securities with remaining maturities of 6 years to 30 years and to sell an equal amount of Treasury securities with remaining maturities of 3 years or less. This program should put downward pressure on longer-term interest rates and help make broader financial conditions more accommodative" (Federal Open Market Committee 2011).
} 


\subsection{Asset purchases}

We interpret LSAP as replacing risky $A$ capital with an equal dollar amount of safe $B$ capital. The direct effect of such a program is to increase aggregate pledgability, and by extension liquidity provision, asset prices, and investment. It can therefore also have an important ex ante effect through collateral values.

We model LSAP as a one-at-a-time intervention to acknowledge fiscal constraints. We assume it takes effect with a given probability immediately following a crash (when it is most needed) and it is eventually withdrawn at a given intensity. This setup introduces a simple binary state variable that corresponds to the state of the central bank's balance sheet (empty or full). Appendix $\mathrm{F}$ shows how to solve the model with this new state variable. Essentially, the pricing equation (23) has to be modified to take into account the possibility for prices to switch between policy states.

Figure 5 implements an LSAP set to reduce the risky asset share $\chi$ by 0.2 . It gets triggered with $50 \%$ probability after a crash and is expected to last ten years.

Figure 5 about here.

The top panels of Figure 5 show that in most of the state-space, LSAP pushes the price of risky capital up and the price of safe capital down, with the effects for both assets being strongest when the capital mix is risky $(\chi=0.9)$. In this region, collateral is scarce and liquidity provision is low. By supplying safe assets, the central bank increases the pledgability of the capital stock, allowing for greater liquidity provision. The result is both a decline in overall discount rates which tends to push all prices up, and a decline in the collateral premium, which pushes the price of risky capital up and the price of safe capital down. The net effect is positive for the risky asset and negative for the safe asset.

Interestingly, enacting a program when liquidity is abundant (when $\chi$ and $\lambda$ are low)

backfires and actually reduces the price of the risky asset. This is the result of the central bank's limited capacity. The economy becomes riskier because the central bank will be out 
of ammunition in the next crash.

Looking along the $\lambda$ dimension, the price effects are strongest when uncertainty is moderately high. This is also the region where collateral runs push haircuts to their highest levels (see Section 3.3). Thus, LSAP is most effective when the shadow banking sector is maximally stressed and contracting quickly.

The middle two panels of Figure 5 consider the ex ante effect of LSAP by comparing prices across economies with and without the possibility of an LSAP intervention. Risky capital prices are higher and safe capital prices are lower in the LSAP economy throughout the state-space, as expected. Importantly, the ex ante effects are stronger than the ex post effects in the low uncertainty region. LSAP has a stabilizing effect ex post when uncertainty is high, which means it boosts collateral values ex ante when uncertainty is low. In this way, LSAP promotes shadow banking booms.

Finally, we consider the effect of an announcement that policy accommodation will be withdrawn sooner than anticipated. ${ }^{29}$ In the lower panels of Figure 5 we show that "taper talk" produces sharp asset price movements in our model as in the data. ${ }^{30}$

\subsection{Operation Twist}

We model Operation Twist as a reduction in the duration of the economy's safe capital. Interestingly, in our framework this can reduce pledgability as long-term safe capital acts as a crash-hedge in the presence of flight to quality. To demonstrate this effect, we use the parameters from Section 3.4 on flight to quality.

We map the safe asset to government debt by assuming that the private sector cannot create it but that the government issues it by following the same policy that intermediaries do in the benchmark economy (set Tobin's $q$ to one). To model a change in duration within

\footnotetext{
${ }^{29}$ In the summer of 2013 , discussion of policy withdrawal, or "taper talk", led to sharp corrections across asset markets.

${ }^{30}$ Our results suggest that expectations of premature policy withdrawal can undermine the effectiveness of an asset purchase program. Woodford (2012) argues that such expectation channel is mute under the market segmentation rationale for the LSAP program.
} 
an economy, we introduce two types of government debt, zero-duration floating-rate debt and long-term fixed coupon bonds. Floating debt pays the floating rate $\mu_{m}$ (the yield of money) and therefore trades at par. Long bonds pay the fixed coupon $\gamma^{b}$ as in the baseline model. The central bank sets the shares of the two types of bonds as a policy variable. Details are in Appendix G.

In an Operation Twist intervention, the central bank buys long-term bonds and sells floating rate bonds of equal dollar amounts. ${ }^{31}$ While anticipated policies are easily implementable in our framework, we focus on a one-off unanticipated intervention in which government debt is restructured from fully long-term to fully floating.

Figure 6 about here.

The left panel of Figure 6 shows that Operation Twist reduces the price of the risky $A$ capital. This is due to a strong flight to quality effect that makes long-term debt appreciate in a crash. As a result, it acts as a hedge for the crash risk of $A$ capital, thereby raising the aggregate supply of collateral. Floating-rate debt always trades at par, so it cannot act as a hedge. In this way, Operation Twist ends up reducing overall pledgability as the bottom panel of Figure 6 shows, which causes discount rates to rise and overall prices to fall. The reduction in collateral supply causes the price of long-term bonds to go up. This means that the effectiveness of Operation Twist cannot be judged solely on the price of long-term bonds which can go up even if the policy is counter-productive.

The case for Operation Twist is predicated on the view that risky productive assets are exposed to duration risk just like long-term bonds, so that reducing the supply of longterm bonds might free up capacity for intermediaries to undertake more risky investment. In our economy the opposite happens because duration turns into a hedge when flight to quality is strong. This makes long-term bonds complements rather than substitutes for risky investment. We return to this discussion in Section 4.4 in the context of the Volcker rule.

\footnotetext{
${ }^{31}$ This kind of policy is proposed by (Greenwood, Hanson, and Stein 2012)
} 


\subsection{Capital requirements}

Capital requirements reduce the amount of liquidity that intermediaries can produce per dollar of assets. We study the impact of an announcement that stricter capital requirements will be implemented at some future date. We can implement capital requirements by simply rewriting the normal-times solvency constraint (14) as $m_{t}+s_{t} \leq 1-\underline{e}$. We characterize the resulting optimal capital structure in Appendix H. The rest of the model is identical to our benchmark setup. Thus, the direct effect of the capital requirement is to reduce the issuance of liquid liabilities in low-uncertainty states. The indirect effect is through equilibrium prices.

Figure 7 about here.

Figure 7 shows the impact of an announcement that a 10\% capital requirement $(\underline{e}=10 \%$ up from 0\%) is expected to be imposed in five years. The top panels plot prices and the bottom panels plot the intermediary capital structure once the capital requirement is in effect.

Following the announcement, overall prices drop, which results in lower growth. When the capital requirement binds, the discount rate increases is offset by a drop in collateral premia, and the price of the productive $A$ capital can actually increase.

Capital requirements have a disproportionate effect on shadow money creation. This is because they curtail the principal advantage of shadow money, the ability to lever up collateral. As the shadow banking sector is particularly sensitive to shocks, this has the effect of increasing "financial stability" in the sense of reducing asset price volatility. Stability is achieved by lowering prices in the boom without increasing them in the bust (high $\chi$, high $\lambda$ ). Nevertheless, capital requirements do provide support to the productive $A$ capital in the slow recovery phase of the cycle (low $\chi$, high $\lambda$ ).

Figure 7 highlights the fact that capital requirements produce price drops even when they do not bind. Asset prices capitalize future funding costs, so higher funding costs when uncertainty is low propagate to lower prices when uncertainty is high. 


\subsection{The Volcker rule}

We interpret the Volcker rule as imposing a segregation between intermediaries that hold risky and safe assets. ${ }^{32}$ At this general level, our analysis could also refer to the reintroduction of the Glass-Steagall act. A full evaluation of the merits of these policies is beyond the scope of our paper. In particular, our framework lacks any notion of moral hazard which is often cited as a rationale for their implementation. Our aim here is to offer a perspective on the implications of risk-based balance sheet segregation for liquidity provision.

The key point is that our model features a complementarity between risky and safe asset holdings whenever flight to quality effects are present. The intuition is the same as in the discussion of Operation Twist: flight to quality makes safe capital act as a hedge for risky capital on the balance sheet, which raises pledgability. Under a Volcker rule, collateral is effectively wasted as a safe bank has too much and a risky bank has too little.

To illustrate, suppose there is flight to quality so that the value of safe capital rises in a crash. Consider a Volcker rule economy with two (types of) intermediaries, a risky-asset bank $i=a$ and a safe-asset bank $i=b$. Each bank's balance sheet must satisfy the solvency constraints (14) and (15), and it holds only one type of capital:

$$
m^{i}+s^{i} \leq \min \left\{1,\left(1-\kappa_{\pi}^{i}\right)\left(1-\kappa^{i}\right)+s^{i} \bar{\kappa}\right\}
$$

Flight to quality implies that the safe bank has excess collateral that allows it to issue 100\% money, $m^{b}=1$ and $s^{b}=0$. The risky bank behaves as in our model, so its crash-solvency constraint binds, $m^{a}+s^{a}=\left(1-\kappa_{\pi}^{a}\right)\left(1-\kappa^{a}\right)+s^{a} \bar{\kappa}$. Let $x$ be the value-weighted share of $A$ capital. Then aggregate liquidity under the Volcker rule versus the benchmark economy is

$$
\begin{aligned}
m^{a}+s^{a}+m^{b}+s^{b} & =x\left(1-\kappa_{\pi}^{a}\right)\left(1-\kappa^{a}\right)+(1-x)+s^{a} \bar{\kappa} \\
m+s & =x\left(1-\kappa_{\pi}^{a}\right)\left(1-\kappa^{a}\right)+(1-x)\left(1-\kappa_{\pi}^{b}\right)\left(1-\kappa^{b}\right)+s \bar{\kappa} .
\end{aligned}
$$

\footnotetext{
${ }^{32}$ Note that liabilities-side segregation (e.g. between issuers of money and shadow money) has no effect in our model as the ability to issue equity costlessly allows capital to flow freely across intermediaries.
} 
Comparing (26) with (27) it is clear that flight to quality, $\left(1-\kappa_{\pi}^{b}\right)\left(1-\kappa^{b}\right)>1$, leads to lower liquidity provision in the Volcker economy. In general both normal-times and crashproof liquidity are lower even though the Volcker rule only reduces pledgability in a crash. The scarcity of collateral on the risky bank's balance sheet reduces its capacity to provide normal-times liquidity with shadow money. At the same time, the excess collateral on the safe bank's balance sheet goes unused.

\section{Conclusion}

Reinhart and Rogoff (2009) document that financial crises are preceded by large debt accumulations and are followed by slow recoveries. In this paper, this interaction between finance and the macroeconomy arises as a result of booms and busts in the supply of liquidity that are initiated by uncertainty shocks and are perpetuated by slow movements in the supply of collateral. Whereas level shocks have limited impact, uncertainty shocks cause discount rates to spike, liquidity provision to contract, and investment to falter. Periods of high uncertainty set the economy on a path toward a collateral-rich but productivity-poor capital stock, leading to a prolonged aftermath that trails the recovery of financial spreads.

Our focus is on the macroeconomic effects of shadow banking which we interpret as the creation of securities that are money-like most of the time but cease to be liquid in the event of a crash. Shadow banking raises liquidity and lowers discount rates, but it also raises the economy's sensitivity to uncertainty shocks. Economic fragility is a consequence of liquidity transformation, the use of scarce collateral to back high levels of liquidity in good states while crowding out liquidity provision in bad states. Nevertheless, if without shadow banking the landing at the cycle's trough is not as hard, it is because the fall was from a lower peak. 


\section{References}

Adrian, Tobias, and Nina Boyarchenko, 2012. Intermediary leverage cycles and financial stability. Working paper.

Adrian, Tobias, Erkko Etula, and Tyler Muir, 2011. Financial intermediaries and the crosssection of asset returns. Working paper.

Adrian, Tobias, Emanuel Moench, and Hyun Song Shin, 2010. Financial intermediation, asset prices, and macroeconomic dynamics. Federal Reserve Bank of New York Staff Report 422.

Adrian, Tobias, and Hyun Song Shin, 2010. Liquidity and leverage. Journal of Financial Intermediation 19, 418 - 437 Risk Transfer Mechanisms and Financial Stability.

Ashcraft, Adam, Nicolae Gârleanu, and Lasse Heje Pedersen, 2011. Two monetary tools: Interest rates and haircuts. in NBER Macroeconomics Annual 2010, Volume 25 . pp. 143-180 University of Chicago Press.

Bansal, Ravi, Wilbur Coleman, and Christian Lundblad, 2010. Endogenous liquidity supply. in AFA 2011 Denver Meetings Paper.

Bernanke, Ben, and Mark Gertler, 1989. Agency costs, net worth, and business fluctuations. The American Economic Review pp. 14-31.

Bernanke, Ben S, 2013. Monitoring the financial system. At the 49th Annual Conference on Bank Structure and Competition sponsored by the Federal Reserve Bank of Chicago, Chicago, Illinois.

— Mark Gertler, and Simon Gilchrist, 1999. The financial accelerator in a quantitative business cycle framework. Handbook of macroeconomics 1, 1341-1393.

Bigio, Saki, 2013. Endogenous liquidity and the business cycle. Working paper.

Brunnermeier, Markus K, Thomas M Eisenbach, and Yuliy Sannikov, 2012. Macroeconomics with financial frictions: A survey. Discussion paper, .

Brunnermeier, Markus K, and Lasse Heje Pedersen, 2009. Market liquidity and funding liquidity. Review of Financial studies 22, 2201-2238.

Brunnermeier, Markus K., and Yuliy Sannikov, 2013. A macroeconomic model with a financial sector. American Economic Review.

Caballero, Ricardo J, and Emmanuel Farhi, 2013. A model of the safe asset mechanism (SAM): Safety traps and economic policy. NBER working paper.

Dang, Tri Vi, Gary Gorton, and Bengt Holmström, 2010. Financial crises and the optimality of debt for liquidity provision. Working paper.

DeAngelo, Harry, and Rene Stulz, 2013. Why high leverage is optimal for banks. Fisher College of Business Working Paper p. 08.

Diamond, Douglas W., and Philip H. Dybvig, 1983. Bank runs, deposit insurance, and liquidity. Journal of Political Economy 91, pp. 401-419. 
Federal Open Market Committee, 2007. Minutes from the meeting of the Federal Open Market Committee on june 27-28, 2007. US Federal Reserve.

— 2008. Press release of november 25, 2008. US Federal Reserve.

— , 2011. Statement following the meeting of the Federal Open Market Committee on september 11, 2011. US Federal Reserve.

Financial Crisis Inquiry Commission, 2011. The financial crisis inquiry report. US Government Printing Office.

Frazzini, Andrea, and Lasse H Pedersen, 2010. Betting against beta. Discussion paper, National Bureau of Economic Research.

Geanakoplos, John, 2003. Liquidity, default, and crashes endogenous contracts in general. in Advances in economics and econometrics: theory and applications: eighth World Congress, Volume II pp. 170-205.

Gennaioli, Nicola, Andrei Shleifer, and Robert W. Vishny, 2013. A model of shadow banking. The Journal of Finance 68, 1331-1363.

Gertler, Mark, and Peter Karadi, 2011. A model of unconventional monetary policy. Journal of Monetary Economics 58, 17-34.

Gertler, Mark, and Nobuhiro Kiyotaki, 2010. in Benjamin M. Friedman, and Michael Woodford, (Ed.): Handbook of Monetary Economics, chap. 11, pp. 547-599. Elsevier.

— , 2013. Banking, liquidity and bank runs in an infinite-horizon economy. Discussion paper, National Bureau of Economic Research.

Gorton, Gary, and Andrew Metrick, 2011. Securitized banking and the run on repo. Journal of Financial Economics.

Gorton, Gary, and George Pennacchi, 1990. Financial intermediaries and liquidity creation. The Journal of Finance 45, 49-71.

Gorton, Gary B, and Guillermo Ordoñez, 2012. Collateral crises. Discussion paper, National Bureau of Economic Research.

Greenwood, Robin, Sam Hanson, and Jeremy Stein, 2012. A comparative-advantage approach to government debt maturity. Discussion paper, mimeo, Harvard.

Hanson, Floyd B., 2007. Applied stochastic processes and control for jump diffusions: Modeling, analysis, and computation Society for Industrial and Applied Mathematics.

He, Zhiguo, In Gu Khang, and Arvind Krishnamurthy, 2010. Balance sheet adjustments during the 2008 crisis. IMF Economic Review 58, 118-156.

He, Zhiguo, and Arvind Krishnamurthy, 2012. Intermediary asset pricing. American Economic Review, forthcoming.

Holmström, Bengt, and Jean Tirole, 1998. Private and public supply of liquidity. Journal of Political Economy 106, 1-40. 
Kiyotaki, Nobuhiro, and John Moore, 1997. Credit cycles. Journal of Political Economy 105. — 2012 . Liquidity, business cycles, and monetary policy. NBER working paper National Bureau of Economic Research.

Krishnamurthy, Arvind, 2010. How debt markets have malfunctioned in the crisis. The Journal of Economic Perspectives 24, 3-28.

— , and Annette Vissing-Jorgensen, 2012a. The aggregate demand for treasury debt. Journal of Political Economy 120, 233-267.

— , 2012b. Short-term debt and financial crises: What we can learn from US Treasury supply. Working paper.

, 2013. The ins and outs of LSAPs. 2013 Federal Reserve Bank of Kansas City Economic Policy Symposium, Jackson Hole, Wyoming.

Kurlat, Pablo, 2012. Lemons markets and the transmission of aggregate shocks. Working paper.

Maggiori, Matteo, 2013. Financial intermediation, international risk sharing, and reserve currencies. Working paper.

McCauley, Robert, and Patrick McGuire, 2009. Dollar appreciation in 2008: safe haven, carry trades, dollar shortage and overhedging. BIS Quarterly Review.

Minsky, Hyman P, 1986. Stabilizing an unstable economy Yale University Press New Haven, CT.

Modigliani, Franco, and Merton H Miller, 1958. The cost of capital, corporation finance and the theory of investment. The American economic review 48, 261-297.

Rampini, Adriano, and S Viswanathan, 2012. Financial intermediary capital. Working paper.

Reinhart, Carmen M, and Vincent R Reinhart, 2010. After the fall. NBER working paper National Bureau of Economic Research.

Reinhart, Carmen M, and Kenneth Rogoff, 2009. This time is different: Eight centuries of financial folly Princeton University Press.

Sannikov, Yuliy, 2013. Quiet times and financial fragility. Working paper.

Simsek, Alp, 2013. Belief disagreements and collateral constraints. Econometrica 81, 1-53.

Sunderam, Adi, 2013. Money creation and the shadow banking system. Working paper.

Woodford, Michael, 2012. Methods of policy accommodation at the interest-rate lower bound. in Jackson Hole symposium, August, Federal Reserve Bank of Kansas City. 


\section{Appendix}

\section{A. Filtering}

Let $\mathcal{F}_{t}$ represent the public information filtration. Agents form beliefs

$$
\lambda_{t}=E\left[\tilde{\lambda}_{t} \mid \mathcal{F}_{t}\right]
$$

We assume agents learn about $\tilde{\lambda}$ from the realization of a jump (or lack thereof) and an additional noisy public signal. Specifically, the innovation to the household filtration $\mathcal{F}$ can be represented by the $2 \times 1$ signal

$$
d e_{t}=\left[\begin{array}{c}
\left(\tilde{\lambda}_{t}-\lambda_{t}\right) d t+\sigma_{e} d \tilde{B}_{t} \\
d N_{t}-\lambda_{t} d t
\end{array}\right]
$$

where $\sigma_{e}>0$ is the noise in the diffusive component of the signal and $\tilde{B}_{t}$ is a standard Brownian motion uncorrelated with all other fundamental shocks.

We seek to compute an innovations representation of the form

$$
d \lambda_{t}=A_{t} d t+B_{t}^{\prime} d e_{t}
$$

Note that

$$
\begin{aligned}
d \lambda_{t} & =E\left[\tilde{\lambda}_{t+d t} \mid \mathcal{F}_{t}, d e_{t}\right]-E\left[\tilde{\lambda}_{t} \mid \mathcal{F}_{t}\right] \\
& =E\left[\tilde{\lambda}_{t}+d \tilde{\lambda}_{t} \mid \mathcal{F}_{t}, d e_{t}\right]-E\left[\tilde{\lambda}_{t} \mid \mathcal{F}_{t}\right] \\
& =\left[-\left(\lambda_{t}-\lambda^{L}\right) q^{H}+\left(\lambda^{H}-\lambda_{t}\right) q^{L}\right] d t+E\left[\tilde{\lambda}_{t} \mid \mathcal{F}_{t}, d e_{t}\right]-E\left[\tilde{\lambda}_{t} \mid \mathcal{F}_{t}\right]
\end{aligned}
$$

The last line follows from the fact that the jump and noisy signal innovations are uncorrelated with the process for $\tilde{\lambda}$. The innovation representation is therefore the conditional mean of the population regression

$$
\tilde{\lambda}_{t}-\lambda_{t}=\left[-\left(\lambda_{t}-\lambda^{L}\right) q^{H}+\left(\lambda^{H}-\lambda_{t}\right) q^{L}\right] d t+B_{t}^{\prime} d e_{t}+\epsilon_{t} .
$$

The orthogonality condition for $\epsilon$ gives

$$
\begin{aligned}
B_{t} & =E\left[d e_{t} d e_{t}^{\prime} \mid \mathcal{F}_{t}\right]^{-1} E\left[d e_{t}\left(\tilde{\lambda}_{t}-\lambda_{t}\right) \mid \mathcal{F}_{t}\right] \\
& =\left[\begin{array}{cc}
\sigma_{e}^{2} d t & 0 \\
0 & \lambda_{t} d t
\end{array}\right]^{-1}\left[\begin{array}{l}
\left(\lambda^{H}-\lambda_{t}\right)\left(\lambda_{t}-\lambda^{L}\right) d t \\
\left(\lambda^{H}-\lambda_{t}\right)\left(\lambda_{t}-\lambda^{L}\right) d t
\end{array}\right] \\
& =\left[\begin{array}{c}
\frac{1}{\sigma_{e}^{2}} \\
\frac{1}{\lambda_{t}}
\end{array}\right]\left(\lambda^{H}-\lambda_{t}\right)\left(\lambda_{t}-\lambda^{L}\right)
\end{aligned}
$$


Therefore, we can write the dynamics of the perceived jump intensity as

$$
\begin{aligned}
d \lambda_{t}= & {\left[-\left(\lambda_{t}-\lambda^{L}\right) q^{H}+\left(\lambda^{H}-\lambda_{t}\right) q^{L}\right] d t+\left(\lambda^{H}-\lambda_{t}\right)\left(\lambda_{t}-\lambda^{L}\right)\left[\begin{array}{cc}
\frac{1}{\sigma_{e}^{2}} & \frac{1}{\lambda_{t}}
\end{array}\right] d e_{t} } \\
= & {\left[-\left(\lambda_{t}-\lambda^{L}\right) q^{H}+\left(\lambda^{H}-\lambda_{t}\right) q^{L}-\left(\lambda^{H}-\lambda_{t}\right)\left(\lambda_{t}-\lambda^{L}\right)\right] d t+\frac{1}{\sigma_{e}} d B_{t} } \\
& +\frac{1}{\lambda_{t}}\left(\lambda^{H}-\lambda_{t}\right)\left(\lambda_{t}-\lambda^{L}\right) d N_{t} .
\end{aligned}
$$

Rearranging,

$$
\frac{d \lambda_{t}}{\left(\lambda^{H}-\lambda_{t}\right)\left(\lambda_{t}-\lambda^{L}\right)}=\left(-\frac{q^{H}}{\lambda^{H}-\lambda_{t}}+\frac{q^{L}}{\lambda_{t}-\lambda^{L}}-1\right) d t+\frac{1}{\sigma_{e}} d B_{t}+\frac{1}{\lambda_{t}} d N_{t} .
$$

This confirms (3).

\section{B. Learning and liquidity}

In this section we show how to motivate our definition of liquidity as a sufficient condition for avoiding information acquisition by arbitrageurs and the resulting adverse selection problem. Consider an arbitrageur who runs a fund with assets under management normalized to one. For simplicity, assume that the fund is short-lived so its investment horizon has length $d t$. At the end of this period, the arbitrageur is compensated for outperforming a leverage-adjusted benchmark composed of the underlying assets.

We consider arbitrageurs in the equity and shadow money markets separately. This allows us to define the liquidity of one asset in isolation from the other. To motivate this assumption, one can think of hedge funds that adhere to specific investment styles.

An equity fund trades money and equity, yielding a rate of return $d S_{t}=d r_{m, t}+w_{t}\left(d r_{e, t}-d r_{m, t}\right)$, where $w_{t}$ is the portfolio weight in equity. On the other hand, her benchmark return is $d I_{t}=d r_{m, t}+\bar{w}_{t}\left(d r_{e, t}-d r_{m, t}\right)$, where $\bar{w}_{t}=E_{t}\left[w_{t} \mid \lambda_{t}\right]$. In order to obtain finite demand, suppose the fund faces a quadratic position cost $\frac{\alpha}{2}\left(w_{t}-\bar{w}_{t}\right)^{2}$. This means that an infinite position is prohibitively expensive. This could be due to some form of risk aversion or more broadly decreasing returns to scale at the trading strategy level.

Let $\vartheta_{t}$ be the LaGrange multiplier for the constraint $\bar{w}_{t}=E_{t}\left[w_{t} \mid \lambda_{t}\right]$. An informed arbitrageur thus maximizes

$$
\begin{aligned}
V_{t} d t= & \max _{w_{t}} E_{t}\left[d S_{t}-d I_{t} \mid \tilde{\lambda}\right]-\frac{\alpha}{2}\left(w_{t}-\bar{w}_{t}\right)^{2} d t+\vartheta_{t}\left(\bar{w}_{t}-E_{t}\left[w_{t} \mid \lambda_{t}\right]\right) d t \\
= & \max _{w_{t}} E_{t}\left[\left(w_{t}-\bar{w}_{t}\right)\left(d r_{e, t}-d r_{m, t}\right) \mid \tilde{\lambda}\right]-\frac{\alpha}{2}\left(w_{t}-\bar{w}_{t}\right)^{2} d t \\
& +\vartheta_{t}\left(\bar{w}_{t}-E_{t}\left[w_{t} \mid \lambda_{t}\right]\right) d t
\end{aligned}
$$

The optimal policy is

$$
w_{t}=\bar{w}_{t}+\frac{1}{\alpha}\left[\mu_{e, t}-\mu_{m, t}-\left(\sigma_{e, t}+\kappa_{e, t}\right)\left(\tilde{\lambda}_{t}-\lambda_{t}\right)-\vartheta_{t}\right] .
$$


Averaging over $\tilde{\lambda}_{t}$ gives $\vartheta_{t}=\mu_{e, t}-\mu_{m, t}$. Therefore,

$$
w_{t}=\bar{w}_{t}-\frac{1}{\alpha}\left(\sigma_{e, t}+\kappa_{e, t}\right)\left(\tilde{\lambda}_{t}-\lambda_{t}\right) .
$$

The resulting maximized objective is

$$
V_{t}=\frac{1}{2 \alpha}\left(\sigma_{e, t}+\kappa_{e, t}\right)^{2}\left(\tilde{\lambda}_{t}-\lambda_{t}\right)^{2}
$$

The ex ante (prior to the learning decision) maximized objective is

$$
E_{t}\left[V_{t} \mid \lambda_{t}\right]=\frac{1}{2 \alpha}\left(\sigma_{e, t}+\kappa_{e, t}\right)^{2} \operatorname{Var}_{t}\left(\tilde{\lambda}_{t} \mid \lambda_{t}\right)
$$

Suppose the cost of learning accrues at a rate $f \operatorname{Var}_{t}\left(\tilde{\lambda}_{t} \mid \lambda_{t}\right)$. Then there will be no learning provided $\frac{1}{2 \alpha}\left(\sigma_{e, t}+\kappa_{e, t}\right)^{2}<f$ or simply

$$
\sigma_{e, t}+\kappa_{e, t}<\sqrt{2 \alpha f}
$$

When this restriction fails to hold, arbitrageurs find it optimal to acquire information. As capital flows into their funds, an adverse selection problem arises, reducing market liquidity. As a result, a household experiencing a liquidity event cannot unload large quantities of equity quickly without incurring substantial costs in the form of price impact or bid-ask spreads. Outside of a liquidity event, households can avoid these costs by trading more patiently or by simply buying and holding. It is with this interpretation in mind that we model the trading of equity in a liquidity event as prohibitive but at other times as costless. By analogy, shadow-money remains liquid as long as

$$
\kappa_{s, t}<\sqrt{2 \alpha f} .
$$

We can therefore equate $\sqrt{2 \alpha f}$ with $\bar{\kappa}$ in the model. This condition ensures that households can liquidate their shadow money holdings quickly at no cost when the need arises as their trading partners can be confident that they are not dealing with privately-informed agents.

\section{Optimal capital structure}

Consider an intermediary whose assets have collateral value $1-\kappa_{A, t}$. Let $l_{t}^{n}$ and $l_{t}^{c}$ be the amount of liquidity the intermediary delivers in normal times and in a crash. The intermediary's liquidity provision problem can be formulated in terms of securities spreads which measure the marginal benefits of liquidity provision:

$$
\max _{l_{t}^{n}, l_{t}^{c}} l_{t}^{c}\left(\mu_{e, t}-\mu_{m, t}\right)+\left(l_{t}^{n}-l_{t}^{c}\right)\left(\mu_{e, t}-\mu_{s, t}\right)
$$


subject to the constraints

$$
\begin{aligned}
& l_{t}^{c} \geq 0, \quad l_{t}^{n} \leq 1-\kappa_{A, t}+\left(l_{t}^{n}-l_{t}^{c}\right) \kappa_{r, t} \\
& l_{t}^{n} \geq l_{t}^{c}, \quad l_{t}^{n} \leq 1 .
\end{aligned}
$$

Crash-proof liquidity $l_{t}^{c}$ receives a full funding cost reduction equal to the equity premium. The incremental liquidity supplied absent a crash, $l_{t}^{n}-l_{t}^{c}$, does not. Crash-proof liquidity must be non-negative and it cannot exceed normal-times liquidity. In turn, normal-times liquidity cannot exceed asset value, and it is also constrained by the availability of collateral after write-offs. Intermediaries always make full use of their collateral in order to take full advantage of the premia households are willing to pay for liquid assets.

We summarize the solution of the liquidity provision problem with the following proposition.

Proposition A.1. For a given level of asset risk $\kappa_{A, t}$, the intermediary's optimal liquidity provision policy is characterized by

i. $l_{t}^{n}=\left(1-\kappa_{A, t}\right) /(1-\bar{\kappa})$ and $l_{t}^{c}=0$ if $\kappa_{A, t} \geq \bar{\kappa}$ and $\kappa_{A, t}>1-\frac{1-\bar{\kappa}}{\eta} \log \left(\frac{\bar{\kappa}}{1-\bar{\kappa}} \frac{e^{-\tau \lambda_{t}}}{1-e^{-\tau \lambda_{t}}}\right)$;

ii. $l_{t}^{n}=1-\kappa_{A, t}$ and $l_{t}^{c}=1-\kappa_{A, t}$ if $\lambda_{t}>-\frac{1}{\tau} \log (1-\bar{\kappa})$;

iii. $l_{t}^{n}=1$ and $l_{t}^{c}=1-\kappa_{A, t} / \bar{\kappa}$ if $\kappa_{A, t} \leq \bar{\kappa}$; and $\kappa_{A, t}<\frac{\bar{\kappa}}{\eta} \log \left(\frac{\bar{\kappa}}{1-\bar{\kappa}} \frac{e^{-\tau \lambda_{t}}}{1-e^{-\tau \lambda_{t}}}\right)$; and

iv. $l_{t}^{n}=1-\kappa_{A, t}+\frac{\bar{\kappa}}{\eta} \log \left(\frac{\bar{\kappa}}{1-\bar{\kappa}} \frac{e^{-\tau \lambda_{t}}}{1-e^{-\tau \lambda_{t}}}\right)$ and $l_{t}^{c}=1-\kappa_{A, t}-\frac{1-\bar{\kappa}}{\eta} \log \left(\frac{\bar{\kappa}}{1-\bar{\kappa}} \frac{e^{-\tau \lambda_{t}}}{1-e^{-\tau \lambda_{t}}}\right)$ otherwise.

Proof. Consider an intermediary whose assets have collateral value $1-\kappa_{A}$. Let $l^{n}$ and $l^{c}$ be the amount of liquidity the intermediary delivers in normal times and in a crash. The intermediary's liquidity provision problem is

$$
\max _{l^{n}, l^{c}} l^{c}\left(\mu_{e}-\mu_{m}\right)+\left(l^{n}-l^{c}\right)\left(\mu_{e}-\mu_{s}\right)
$$

subject to the constraints with associated multipliers

$$
\begin{array}{lll}
\theta_{0}^{c}: & l^{c} \geq 0 & \theta_{0}^{n}: \quad l^{n} \geq l^{c} \\
\theta^{c}: & l^{n} \leq 1-\kappa_{A}+\left(l^{n}-l^{c}\right) \kappa_{r} & \theta^{n}: \quad l^{n} \leq 1 .
\end{array}
$$

Clearly $\kappa_{r}=\bar{\kappa}$ is optimal as it relaxes the collateral constraint. We substitute $\kappa_{r}=\bar{\kappa}$ from here on.

The LaGrangian is

$$
\begin{array}{cl}
\max _{l^{n}, l^{c}} & l^{c}\left(\mu_{e}-\mu_{m}\right)+\left(l^{n}-l^{c}\right)\left(\mu_{e}-\mu_{s}\right)+\theta_{0}^{c} l^{c}+\theta_{0}^{n}\left(l^{n}-l^{c}\right) \\
& +\theta^{c}\left[1-\kappa_{A}+\left(l^{n}-l^{c}\right) \bar{\kappa}-l^{n}\right]+\theta^{n}\left(1-l^{n}\right) .
\end{array}
$$

The optimality conditions are

$$
\begin{aligned}
\mu_{e}-\mu_{m} & =\theta^{c}+\theta^{n}-\theta_{0}^{c} \\
\mu_{e}-\mu_{s} & =(1-\bar{\kappa}) \theta^{c}+\theta^{n}-\theta_{0}^{n} .
\end{aligned}
$$


Since $\mu_{e}-\mu_{m}>\mu_{e}-\mu_{s}$, we have $\bar{\kappa} \theta^{c}>\theta_{0}^{c}-\theta_{0}^{n}$.

Case $(i)$ : Suppose $\theta_{0}^{c}>0$ so $l^{c}=0$. We must have $\theta^{c}>0$. (To see why, suppose $\theta^{c}=0$. Then since $\mu_{e}-\mu_{m}>0, \theta^{n}>0$ but then $l^{n}=1$ and so $\theta_{n}^{0}=0$. But then $\bar{\kappa} \theta^{c}>\theta_{0}^{c}-\theta_{0}^{n}$ cannot hold.) Therefore $l^{n}=1-\kappa_{A}+\left(l^{n}-l^{c}\right) \bar{\kappa}$ and so $l^{n}=\left(1-\kappa_{A}\right) /(1-\bar{\kappa})$. This requires $\kappa_{A} \geq \bar{\kappa}$. It follows that $\theta_{0}^{n}=\theta^{n}=0$. Substituting for the spreads gives $\theta^{c}-$ $\theta_{0}^{c}=h(\psi-1)\left[e^{-\tau \lambda} e^{-\eta\left(\frac{1-\kappa A}{1-\bar{\kappa}}\right)}+\left(1-e^{-\tau \lambda}\right)\right]$ and $(1-\bar{\kappa}) \theta^{c}=h(\psi-1) e^{-\tau \lambda} e^{-\eta\left(\frac{1-\kappa_{A}}{1-\bar{\kappa}}\right)}$. Then $\theta_{0}^{c}=h(\psi-1)\left[\frac{\bar{\kappa}}{1-\bar{\kappa}} e^{-\tau \lambda} e^{-\eta\left(\frac{1-\kappa_{A}}{1-\bar{\kappa}}\right)}-\left(1-e^{-\tau \lambda}\right)\right]$ and $\theta^{c}=h(\psi-1) \frac{1}{1-\bar{\kappa}} e^{-\tau \lambda} e^{-\eta\left(\frac{1-\kappa_{A}}{1-\bar{\kappa}}\right)}$. Since $\theta_{0}^{c}>0, \kappa_{A}>1-\frac{1-\bar{\kappa}}{\eta} \log \left(\frac{\bar{\kappa}}{1-\bar{\kappa}} \frac{e^{-\tau \lambda}}{1-e^{-\tau \lambda}}\right)$.

Case $(i i)$ : Suppose $\theta_{0}^{n}>0$ so $l^{n}=l^{c}$. Since $\kappa_{A}>0, l^{n}<1$ so $\theta^{n}=0$. Since $\mu_{R}-\mu_{r}>0$, $\theta^{c}>0$, so $l^{n}=l^{c}=1-\kappa_{A}$. This implies that $\theta_{0}^{c}=0$. Substituting for the spreads, $\theta^{c}=h(\psi-1) e^{-\eta\left(1-\kappa_{A}\right)}$ and $(1-\bar{\kappa}) \theta^{c}-\theta_{n}^{0}=h(\psi-1) e^{-\tau \lambda} e^{-\eta\left(1-\kappa_{A}\right)}$. Therefore, $\theta_{n}^{0}=$ $h(\psi-1)\left[(1-\bar{\kappa})-e^{-\tau \lambda}\right] e^{-\eta\left(1-\kappa_{A}\right)}$. This case requires $\lambda>-\frac{1}{\tau} \log (1-\bar{\kappa})$.

Case (iii): Suppose $\theta^{n}>0$ so $l^{n}=1$. Since $\kappa_{A}>0, \theta_{n}^{0}=0$. Then from $\bar{\kappa} \theta^{c}>\theta_{0}^{c}-\theta_{0}^{n}$, $\theta^{c}>0$ so $l^{c}=1-\kappa_{A} / \bar{\kappa}$, which requires $\kappa_{A} \leq \bar{\kappa}$ and gives $\theta_{0}^{c}=0$. Substituting for the spreads, $\theta^{c}+\theta^{n}=h(\psi-1)\left[e^{-\tau \lambda} e^{-\eta}+\left(1-e^{-\tau \lambda}\right) e^{-\eta\left(1-\frac{\kappa_{A}}{\bar{\kappa}}\right)}\right]$ and $(1-\bar{\kappa}) \theta^{c}+\theta_{n}=$ $h(\psi-1) e^{-\tau \lambda} e^{-\eta}$. So $\theta^{n}=h(\psi-1)\left[e^{-\tau \lambda} e^{-\eta}+\left(1-\frac{1}{\bar{\kappa}}\right)\left(1-e^{-\tau \lambda}\right) e^{-\eta\left(1-\frac{\kappa_{A}}{\bar{\kappa}}\right)}\right]$ and $\theta^{c}=$ $\frac{1}{\bar{\kappa}} h(\psi-1)\left(1-e^{-\tau \lambda}\right) e^{-\eta\left(1-\frac{\kappa_{A}}{\bar{\kappa}}\right)}$. This also requires $\kappa_{A}<\frac{\bar{\kappa}}{\eta} \log \left(\frac{\bar{\kappa}}{1-\bar{\kappa}} \frac{e^{-\tau \lambda}}{1-e^{-\tau \lambda}}\right)$.

Case $(i v)$ : Suppose $\theta_{0}^{c}=\theta_{0}^{n}=\theta^{n}=0$. Then $\theta^{c}>0$ and $l^{n}=1-\kappa_{A}+\left(l^{n}-l^{c}\right) \bar{\kappa}$. Substituting for the spreads, $h(\psi-1)\left[e^{-\tau \lambda} e^{-\eta l^{n}}+\left(1-e^{-\tau \lambda}\right) e^{-\eta l^{c}}\right]=(1-\bar{\kappa}) h(\psi-1)\left[e^{-\tau \lambda} e^{-\eta l^{n}}\right]$. Solving, $l^{n}=1-\kappa_{A}+\frac{\bar{\kappa}}{\eta} \log \left(\frac{\bar{\kappa}}{1-\bar{\kappa}} \frac{e^{-\tau \lambda}}{1-e^{-\tau \lambda}}\right), l^{c}=1-\kappa_{A}-\frac{1-\bar{\kappa}}{\eta} \log \left(\frac{\bar{\kappa}}{1-\bar{\kappa}} \frac{e^{-\tau \lambda}}{1-e^{-\tau \lambda}}\right)$, and $\theta^{c}=$ $h(\psi-1) e^{-\eta\left(1-\kappa_{A}\right)}\left(\frac{e^{-\tau \lambda}}{1-\bar{\kappa}}\right)^{1-\bar{\kappa}}\left(\frac{1-e^{-\tau \lambda}}{\bar{\kappa}}\right)^{\bar{\kappa}}$.

We can now show that the optimal liquidity provision policy characterized in Proposition A.1 can be implemented with money, shadow money, and equity as given in Proposition 1 in the text:

Proof of Proposition 1. We already showed that $\kappa_{r, t}=\bar{\kappa}$ is optimal above.

Case $(i)$ : The optimal capital structure can be implemented with $m=0$ and $s=\left(1-\kappa_{A}\right) /(1-\bar{\kappa})$. Therefore, equity is $1-m-s=\left(\kappa_{A}-\bar{\kappa}\right) /(1-\bar{\kappa})$. As all collateral is used to back shadow money, $\kappa_{e, t}=1$ so equity is wiped out in a crash and is therefore illiquid. Optimal liquidity provision requires shadow money but not money.

Case $(i i)$ : The optimal liquidity supply can be implemented with $m=1-\kappa_{A}, s=0$. Equity is $1-m-s=\kappa_{A}$ and is thus wiped out in a crash, $\kappa_{e, t}=1$. Since $\sigma_{A} \geq 0$ (asset value is decreasing in $\lambda$ ), equity is illiquid. The optimal policy can be implemented without shadow money but not without money or equity.

Case (iii): The optimal capital structure can be implemented with $w^{m}=1-\kappa_{A} / \bar{\kappa}$ and $s=\kappa_{A} / \bar{\kappa}$. Normal-times risk is concentrated on equity, $\sigma_{e, t}=\infty$. Without loss of generality, $\kappa_{e, t}=1$. Equity is illiquid. Optimal liquidity provision requires all three securities.

Case $(i v)$ : The optimal capital structure can be implemented with $m=\left(1-\kappa_{A}\right)-\frac{1-\bar{\kappa}}{\eta} \log \left(\frac{\bar{\kappa}}{1-\bar{\kappa}} \frac{e^{-\tau \lambda}}{1-e^{-\tau \lambda}}\right)$ and $s=\frac{1}{\eta} \log \left(\frac{\bar{\kappa}}{1-\bar{\kappa}} \frac{e^{-\tau \lambda}}{1-e^{-\tau \lambda}}\right)$. Since $m+(1-\bar{\kappa}) s=1-\kappa_{A}$, all collateral is pledged, so equity 
is again wiped out in a crash, $\kappa_{e, t}=1$, so it cannot be liquid.

\section{Numerical solution}

Using the adjustment cost function $\phi(\iota)=\frac{1}{\varphi}(\sqrt{1+2 \varphi \iota}-1)$, the optimality conditions for capital become

$$
\begin{aligned}
\mu_{R}-\theta\left(1-\kappa_{\pi}^{a}\right)\left(1-\kappa^{a}\right)-\theta^{1} & =\frac{\gamma^{a}+\frac{1}{2 \varphi}}{\pi^{a}}+\frac{\pi^{a}}{2 \varphi}+\mu_{\pi}^{a}-\frac{1}{\varphi}-\delta+\kappa^{a} \kappa_{\pi}^{a} \lambda \\
\mu_{R}-\theta\left(1-\kappa_{\pi}^{b}\right)\left(1-\kappa^{b}\right)-\theta^{1} & =\frac{\gamma^{b}+\frac{1}{2 \varphi}}{\pi^{b}}+\frac{\pi^{b}}{2 \varphi}+\mu_{\pi}^{b}-\frac{1}{\varphi}-\delta+\kappa^{b} \kappa_{\pi}^{b} \lambda .
\end{aligned}
$$

Substituting for the investment cost function and the investment optimality conditions into (2), the dynamics of $\chi$ are

$$
\begin{aligned}
d \chi= & \mu(1-2 \chi) d t+\chi(1-\chi)\left[\frac{\pi^{a}-\pi^{b}}{\varphi}+\lambda\left(\kappa^{a}-\kappa^{b}\right)\right] d t \\
& -\chi(1-\chi)\left[\frac{\kappa^{a}-\kappa^{b}}{\chi\left(1-\kappa^{a}\right)+(1-\chi)\left(1-\kappa^{b}\right)}\right] d N .
\end{aligned}
$$

To get the dynamics of $\pi^{a}$ and $\pi^{b}$, apply Ito's Lemma:

$$
\begin{aligned}
\frac{d \pi^{a}}{\pi^{a}}= & {\left[\frac{\pi_{\lambda}^{a}}{\pi^{a}}\left(\lambda-\lambda^{L}\right)\left(\lambda^{H}-\lambda\right)\left(-\frac{q^{H}}{\lambda^{H}-\lambda}+\frac{q^{L}}{\lambda-\lambda^{L}}-1\right)\right.} \\
& +\frac{1}{2} \frac{\pi_{\lambda \lambda}^{a}}{\pi^{a}}\left(\lambda-\lambda^{L}\right)^{2}\left(\lambda^{H}-\lambda\right)^{2} \frac{1}{\sigma_{e}^{2}} \\
& \left.+\frac{\pi_{\chi}^{a}}{\pi^{a}} \chi(1-\chi)\left(\mu\left(\frac{1}{\chi}-\frac{1}{1-\chi}\right)+\frac{1}{\varphi}\left(\pi^{a}-\pi^{b}\right)+\lambda\left(\kappa^{a}-\kappa^{b}\right)\right)\right] d t \\
& +\frac{\pi_{\lambda}^{a}}{\pi^{a}}\left(\lambda-\lambda^{L}\right)\left(\lambda^{H}-\lambda\right) \frac{1}{\sigma_{e}} d B \\
& -\left[1-\frac{\pi^{a}\left(\lambda+\frac{1}{\lambda}\left(\lambda-\lambda^{L}\right)\left(\lambda^{H}-\lambda\right), \chi-\frac{\chi(1-\chi)\left(\kappa^{a}-\kappa^{b}\right)}{\chi\left(1-\kappa^{a}\right)+(1-\chi)\left(1-\kappa^{b}\right)}\right)}{\pi^{a}}\right] d N
\end{aligned}
$$

and similarly for $\pi^{b}$. We solve for $\pi^{a}$ and $\pi^{b}$ using projection methods. 


\section{E. State-space density}

Let $f_{t}(\lambda, \chi)$ be the joint density of $\lambda$ and $\chi$ at $t$ given initial density $f_{0}(\lambda, \chi)$. We calculate $f$ by solving the associated forward Kolmogorov equation (Hanson 2007, Theorem 7.7):

$$
\begin{aligned}
\frac{\partial f_{t}}{\partial t}= & -\frac{\partial}{\partial \lambda}\left(\mu_{\lambda} f_{t}\right)-\frac{\partial}{\partial \chi}\left(\mu_{\chi} f_{t}\right)+\frac{1}{2} \frac{\partial^{2}}{\partial \lambda^{2}}\left(\sigma_{\lambda}^{2} f_{t}\right) \\
& +\left[\lambda^{-} f_{t}\left(\lambda^{-}, \chi^{-}\right)\left|\frac{\partial \lambda^{-}}{\partial \lambda}\right|\left|\frac{\partial \chi^{-}}{\partial \chi}\right|-\lambda f_{t}(\lambda, \chi)\right] .
\end{aligned}
$$

We have

$$
\begin{aligned}
\frac{\partial}{\partial \lambda}\left(\mu_{\lambda} f_{t}\right)= & {\left[2 \lambda-\left(q^{H}+q^{L}\right)-\left(\lambda^{H}+\lambda^{L}\right)\right] f_{t} } \\
& +\left[-q^{H}\left(\lambda-\lambda^{L}\right)+q^{L}\left(\lambda^{H}-\lambda\right)-\left(\lambda-\lambda^{L}\right)\left(\lambda^{H}-\lambda\right)\right] \frac{\partial f_{t}}{\partial \lambda} \\
\frac{\partial}{\partial \chi}\left(\mu_{\chi} f_{t}\right)= & {\left[\frac{1}{\varphi}\left(\pi^{a}-\pi^{b}\right)+\lambda\left(\kappa^{a}-\kappa^{b}\right)\right]\left[(1-2 \chi) f_{t}+\chi(1-\chi) \frac{\partial f_{t}}{\partial \chi}\right] } \\
& +\mu\left[(1-2 \chi) \frac{\partial f_{t}}{\partial \chi}-2 f_{t}\right]+\frac{1}{\varphi}\left(\pi_{\chi}^{a}-\pi_{\chi}^{b}\right) \chi(1-\chi) f_{t} \\
\frac{\partial^{2}}{\partial \lambda^{2}}\left(\sigma_{\lambda}^{2} f_{t}\right)= & 2\left[\left(\frac{\partial \sigma_{\lambda}}{\partial \lambda}\right)^{2}+\sigma_{\lambda}\left(\frac{\partial^{2} \sigma_{\lambda}}{\partial \lambda^{2}}\right)\right] f_{t}+4 \sigma_{\lambda}\left(\frac{\partial \sigma_{\lambda}}{\partial \lambda}\right) \frac{\partial f_{t}}{\partial \lambda}+\sigma_{\lambda}^{2} \frac{\partial^{2} f_{t}}{\partial \lambda^{2}}
\end{aligned}
$$

where $\sigma_{\lambda}=\left(\lambda-\lambda^{L}\right)\left(\lambda^{H}-\lambda\right) \frac{1}{\sigma_{e}}, \frac{\partial \sigma_{\lambda}}{\partial \lambda}=\left(\lambda^{L}+\lambda^{H}-2 \lambda\right) \frac{1}{\sigma_{e}}$, and $\frac{\partial^{2} \sigma_{\lambda}}{\partial \lambda^{2}}=-\frac{2}{\sigma_{e}}$. The pre-jump state values $\lambda^{-}$and $\chi^{-}$are given by

$$
\begin{aligned}
\lambda^{-} & =\frac{\lambda^{L} \lambda^{H}}{\lambda^{L}+\lambda^{H}-\lambda} \\
\chi^{-} & =\frac{1}{1+\left(\frac{1-\kappa^{a}}{1-\kappa^{b}}\right)\left(\frac{1-\chi}{\chi}\right)}
\end{aligned}
$$

with $\frac{\partial \lambda^{-}}{\partial \lambda}=\frac{\lambda^{L} \lambda^{H}}{\left(\lambda^{L}+\lambda^{H}-\lambda\right)^{2}}$ and $\frac{\partial \chi^{-}}{\partial \chi}=\frac{\left(\frac{1-\kappa^{a}}{1-\kappa^{b}}\right)\left(\frac{1}{\chi^{2}}\right)}{\left[1+\left(\frac{1-\kappa^{a}}{1-\kappa^{b}}\right)\left(\frac{1-\chi}{\chi}\right)\right]^{2}}$.

\section{F. Implementation of asset purchases}

Let $\zeta_{t} \in\left\{\zeta_{E}, \zeta_{F}\right\}$ denote the state of the central bank's balance sheet which is either "empty" $\left(\zeta_{t}=\zeta_{E}\right)$ or "full" $\left(\zeta_{t}=\zeta_{F}\right)$. An empty balance sheet is filled with probability $\beta_{L S A P}\left(\lambda_{t}, \chi_{t}\right)$ immediately after a crash in which case it becomes full. ${ }^{33}$ The size of the program is given as a state-contingent fraction $\alpha\left(\lambda_{t}, \chi_{t}\right)$ of the outstanding supply of type- $A$ capital. A full balance sheet is emptied $\left(\zeta_{t}=\zeta_{E}\right)$ with intensity $\beta_{T A P E R}\left(\lambda_{t}, \chi_{t}\right)$.

\footnotetext{
${ }^{33}$ By tying interventions to cash flow shocks we avoid having to introduce separate policy jumps that may add additional binding constraints on intermediary balance sheets.
} 
We nest a permanent and transitory LSAP programs with $\beta_{T A P E R}\left(\lambda_{t}, \chi_{t}\right)=0$ under a permanent policy and $\beta_{\text {TAPER }}\left(\lambda_{t}, \chi_{t}\right)>0$ under a transitory policy. We can express prices as $\pi_{t}^{i}=\pi^{i}\left(\lambda_{t}, \chi_{t}, \zeta_{t}\right)$ for $i=a, b$. The drift and pledgability of prices when $\zeta_{t}=\zeta_{E}$ are

$$
\begin{aligned}
\mu_{\pi, \zeta_{E}}^{i} & =\mu_{\pi, \zeta_{0}}^{i}-\lambda \beta_{L S A P}\left(\kappa_{\pi, L S A P}^{i}-\kappa_{\pi}^{i}\right) \\
1-\kappa_{\pi, \zeta_{E}}^{i} & =\min \left\{1-\kappa_{\pi, L S A P}^{i}, 1-\kappa_{\pi}^{i}\right\}
\end{aligned}
$$

for $i=a, b$ where $\mu_{\pi, \zeta_{0}}^{i}$ is given in (59), $1-\kappa_{\pi, L S A P}^{i}=\frac{\pi^{i}\left(\lambda_{+}, \chi_{+}-\alpha, \zeta_{F}\right)}{\pi\left(\lambda, \chi, \zeta_{E}\right)}$ (LSAP shifts $\chi^{+}$to $\left.\chi^{+}-\alpha\right)$, and $1-\kappa_{\pi}^{i}=\frac{\pi\left(\lambda_{+}, \chi_{+}, \zeta_{E}\right)}{\pi\left(\lambda, \chi, \zeta_{E}\right)}$. These modified dynamics enter into (23). Under $\zeta_{t}=\zeta_{F}$, we have

$$
\mu_{\pi, \zeta_{F}}^{i}=\mu_{\pi, \zeta_{0}}^{i}-\beta_{T A P E R} \kappa_{\pi, T A P E R}^{i}
$$

for $i=a, b$ with $1-\kappa_{\pi, T A P E R}=\frac{\pi\left(\lambda, \chi+\alpha, \zeta_{E}\right)}{\pi^{i}\left(\lambda, \chi, \zeta_{F}\right)}$. To keep things simple, we do not impose solvency constraints with respect to the reversal shock. This has the effect of understating the impact of policy withdrawal. In addition, the policy's entry and exit are generally not of equal size as the economy drifts in the meantime. In this case one can think of the central bank's balance sheet as retaining a residual position.

We measure the announcement effect of an LSAP program as the difference in crash returns with and without the intervention, $\kappa_{\pi}^{i}-\kappa_{\pi, L S A P}^{i}$. A policy reversal shock is measured analogously as $\frac{\pi^{i}\left(\lambda, \chi-\alpha, \zeta_{E}\right)}{\pi^{i}\left(\lambda, \chi, \zeta_{F}\right)}-1$. We measure the effect of an unanticipated tapering shock that raises $\beta_{T A P E R}$ as $\frac{\pi^{i}\left(\lambda, \chi, \zeta_{F} \mid \beta_{T A P E R}^{H}\right)}{\pi^{i}\left(\lambda, \chi, \zeta_{F} \mid \beta_{T A P E R}^{L}\right)}-1$.

In the case of a permanent intervention, the economy at $\zeta_{t}=\zeta_{F}$ corresponds to the benchmark economy and we can solve backwards to obtain prices under $\zeta_{E}$. When interventions are transitory, there is two-way flow between $\zeta_{E}$ and $\zeta_{F}$ and we solve for prices under the two regimes simultaneously.

\section{G. Operation Twist}

We map the safe asset $k^{b}$ to government debt by assuming that the private sector cannot create it but that the government issues it at the same rate as in the baseline model. ${ }^{34}$ To model a change in duration within a given economy, we split type $k^{b}$ capital into two pieces: zero-duration floating-rate debt $k^{f b}$ and long-duration safe bonds $k^{l b}$ (so $k_{t}^{b}=k_{t}^{f b}+k_{t}^{l b}$ ). Floating debt pays the floating rate $\mu_{m}$ (the yield of money) and trades at par in equilibrium. Long bonds pay the fixed coupon $\gamma^{b}$ as in the baseline model. We avoid introducing an additional state variable by assuming that the central bank sets the relative shares $\alpha_{t}=$ $k_{t}^{f b} / k_{t}^{b}$ and $1-\alpha_{t}=k_{t}^{l b} / k_{t}^{b}$ as a policy variable.

In an Operation Twist intervention, the central bank buys long-term bonds and sells floating rate bonds of equal dollar amounts at after-announcement prices. This changes their relative shares $\alpha_{t}$ and $1-\alpha_{t}$. Operation twist changes the composition of government debt $(\alpha)$, while

\footnotetext{
${ }^{34}$ Specifically, private investment $\iota_{t}^{b}$ is restricted to zero in the pricing equation (23). Existing long bonds depreciate on the balance sheet but the government controls their aggregate supply by setting issuance to $d k_{t}^{l b}=\left[\phi\left(\iota_{t}^{l b}\right)-\delta\right] d t$ absent a policy shock with $\pi_{t}^{l b} \phi^{\prime}\left(\iota_{t}^{l b}\right)=1$ and similarly for $d k_{t}^{f b}$.
} 
keeping its value constant. The change in the quantity of government debt is characterized as follows:

Let $x_{-}$and $x_{+}$denote the pre- and post-intervention values of a given quantity $x$. For example $\pi_{+}^{b l}$ is the post-intervention price of the long-term bond. Assuming that the government trades at post-announcement prices and that the intervention does not change the overall value of government liabilities, the pre- and post- quantities must respect

$$
k_{-}^{B}\left[\alpha_{-} \pi_{+}^{b s}+\left(1-\alpha_{-}\right) \pi_{+}^{b l}\right]=k_{+}^{B}\left[\alpha_{+} \pi_{+}^{b s}+\left(1-\alpha_{+}\right) \pi_{+}^{b l}\right] .
$$

We solve for net new issuance $\frac{k_{+}^{B}}{k_{-}^{B}}$ as a function of equilibrium prices and the change in the debt maturity mix $\alpha_{+}-\alpha_{-}$.

\section{H. Capital requirements}

The solution to the intermediary capital structure problem in the presence of capital requirements is characterized by

Proposition A.1. Let $\underline{e}$ be the minimum equity capital requirement, the intermediary's optimal liquidity provision policy is implemented by

i. $m_{t}=1-\underline{e}$ and $s_{t}=0$ if $\kappa_{A, t} \leq \underline{e}$;

ii. $m_{t}=1-\underline{e}-\frac{\kappa_{A, t}-\underline{e}}{\bar{\kappa}}$ and $s_{t}=\frac{\kappa_{A, t}-\underline{e}}{\bar{\kappa}}$ if $\kappa_{A, t} \leq \underline{e}+\bar{\kappa}$ and $\kappa_{A, t}<\underline{e}+\frac{\bar{\kappa}}{\eta} \log \left(\frac{\bar{\kappa}}{1-\bar{\kappa}} \frac{e^{-\tau \lambda_{t}}}{1-e^{-\tau \lambda_{t}}}\right)$;

iii. $m_{t}=0$ and $s_{t}=\left(1-\kappa_{A, t}\right) /(1-\bar{\kappa})$ if $\kappa_{A, t}>\bar{\kappa}+\underline{e}-\underline{e} \bar{\kappa}$ and $\kappa_{A, t}>1-\frac{1-\bar{\kappa}}{\eta} \log \left(\frac{\bar{\kappa}}{1-\bar{\kappa}} \frac{e^{-\tau \lambda_{t}}}{1-e^{-\tau \lambda_{t}}}\right)$;

iv. $m_{t}=1-\kappa_{A, t}$ and $s_{t}=0$ if $\lambda_{t}>-\frac{1}{\tau} \log (1-\bar{\kappa})$ and $\kappa_{A, t} \geq \underline{e}$;

v. $m_{t}=\left(1-\kappa_{A, t}\right)-\frac{1-\bar{\kappa}}{\eta} \log \left(\frac{\bar{\kappa}}{1-\bar{\kappa}} \frac{e^{-\tau \lambda_{t}}}{1-e^{-\tau \lambda_{t}}}\right)$ and $s_{t}=\frac{1}{\eta} \log \left(\frac{\bar{\kappa}}{1-\bar{\kappa}} \frac{e^{-\tau \lambda_{t}}}{1-e^{-\tau \lambda_{t}}}\right)$ otherwise.

Proof of Proposition A.1. The proof follows the recipe from Propositions A.1 and 1 under the modified normal-times solvency constraint $m_{t}+s_{t} \leq 1-\underline{e}$. 
Table I. Benchmark parameter values

This table contains the values for the model parameters used for producing the benchmark results of the paper.

\begin{tabular}{lrr} 
Description & Parameter & Value \\
\hline & & \\
Subjective discounting parameter & $\rho$ & 0.40 \\
Depreciation & $\kappa$ & 0.03 \\
Level-inflow & $\varphi$ & 0.01 \\
Investment adjustment cost & $\kappa^{a}$ & 5 \\
Type- $A$ cash flow risk & $\kappa^{b}$ & 0.4 \\
Type- $B$ cash flow risk & $\gamma^{a}$ & 0.0 \\
Type- $A$ productivity & $\gamma^{b}$ & 0.08 \\
Type- $B$ productivity & $\lambda^{L}$ & 0.03 \\
Low uncertainty state & $\lambda^{H}$ & 0.1 \\
High uncertainty state & $q^{L}$ & 2.1 \\
Low uncertainty state exit rate & $q^{H}$ & 0.05 \\
High uncertainty state exit rate & $1 / \sigma_{e}$ & 0.05 \\
Uncertainty news signal precision & $\bar{\kappa}$ & 0.1 \\
Liquid asset risk upper bound & $\tau$ & 0.7 \\
Liquidity event duration & $h$ & 1.032 \\
Liquidity event intensity & $\psi$ & 0.1 \\
Value of liquidity-event consumption & $1 / \eta$ & 10 \\
Average liquidity shock size & & 0.5 \\
\hline
\end{tabular}


Figure 1. Prices, issuance, growth, and liquidity consumption

This figure plots capital prices, money issuance, shadow money issuance, output growth, and liquidity services using the benchmark parameter values in Table 1. Each quantity is plotted against uncertainty $\lambda$ while holding the capital mix $\chi$ fixed at a low (0.1), medium (0.5), and high (0.9) level. Growth is the expected growth rate of output $y_{t}=\gamma^{a} k_{t}^{a}+\gamma^{b} k_{t}^{b}$. Liquidity consumption is the flow rate of $E_{t}\left[C_{t} d N_{t}^{h}\right]$.

Asset A price $\left(\pi^{a}\right)$

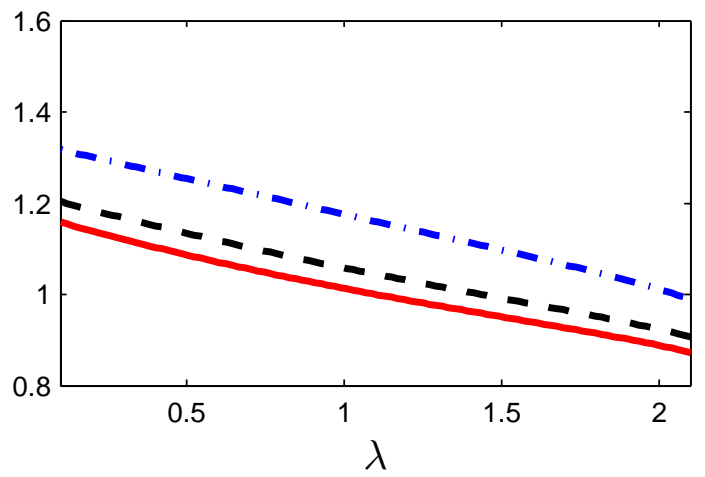

Money $(m)$

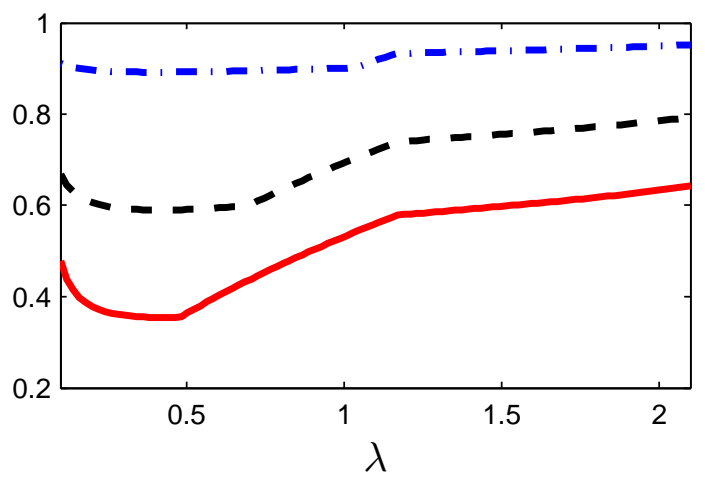

Liquidity consumption

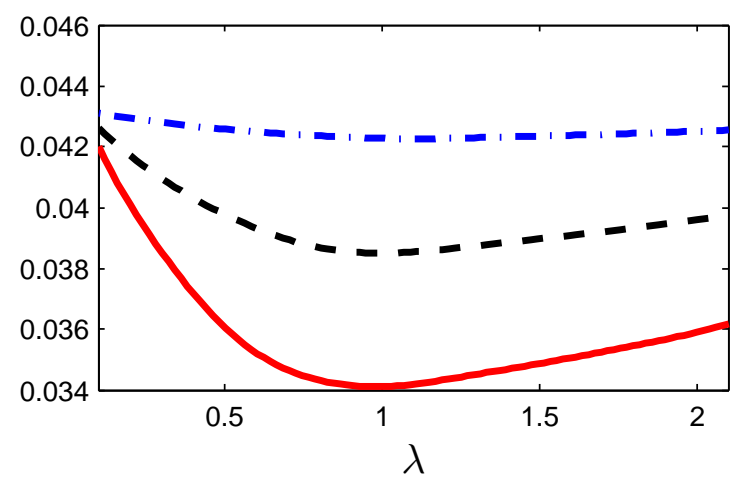

Asset B price $\left(\pi^{b}\right)$

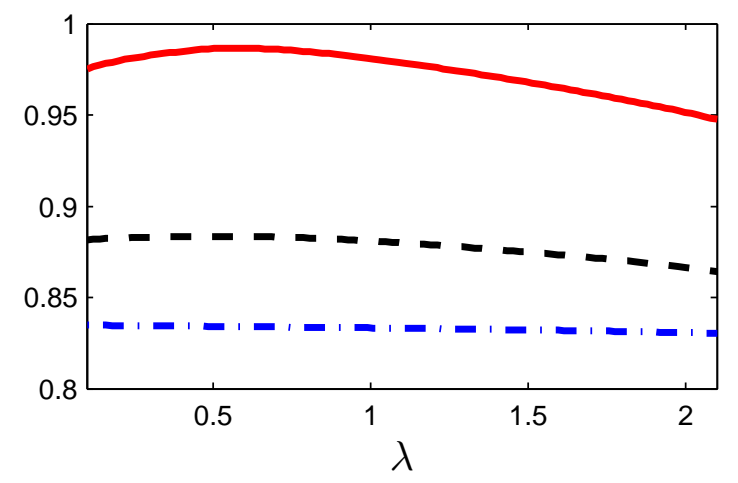

Shadow money $(s)$

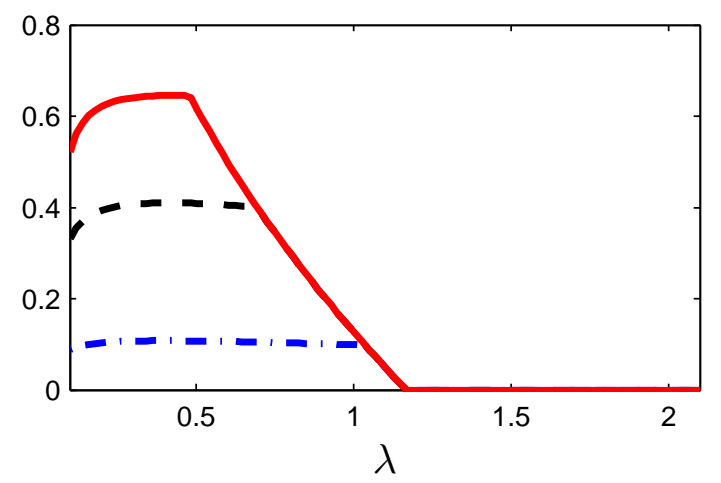

Growth

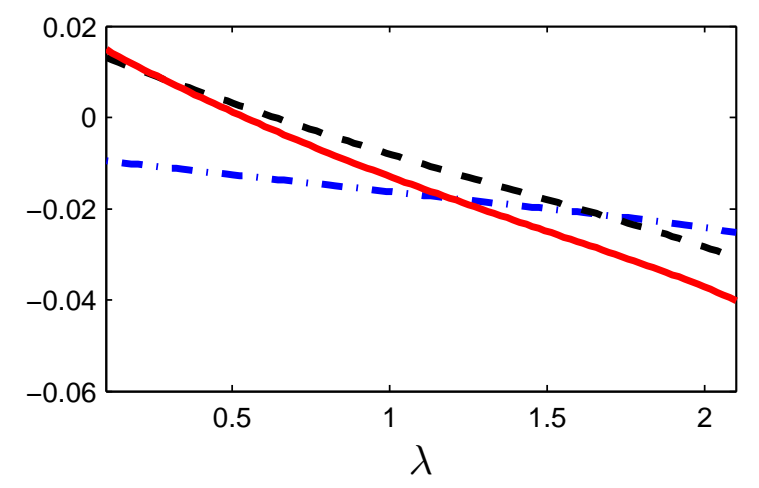

$$
\boldsymbol{- \boldsymbol { - } \chi} \chi=0.1 \quad-\boldsymbol{\chi} \chi=0.5 \longrightarrow \chi=0.9
$$




\section{Figure 2. Persistence}

The evolution of uncertainty $\lambda$, and the capital mix $\chi$ over time starting from a initial condition of low (left, $\lambda_{0}=0.6$ ) or high (right, $\lambda_{0}=1.6$ ) levels of $\lambda$, and low $\left(\chi_{0}=0.1\right.$ ), medium $\left(\chi_{0}=0.5\right)$, or high $\left(\chi_{0}=0.9\right)$ levels of $\chi$. The top two panels show the evolution of $\lambda$ (which is independent of $\chi$ ) with solid red lines for the conditional mean of $\lambda, E_{0}\left[\lambda_{t} \mid \lambda_{0}\right]$, and gray shading for the conditional density of $\lambda$. The bottom panels show the conditional means of $\chi, E_{0}\left[\chi_{t} \mid \lambda_{0}, \chi_{0}\right]$. The conditional means and densities are computed using the forward Kolmogorov equation in Appendix E.

Low initial uncertainty

$$
E\left[\lambda_{t} \mid \lambda_{0}=0.6\right]
$$
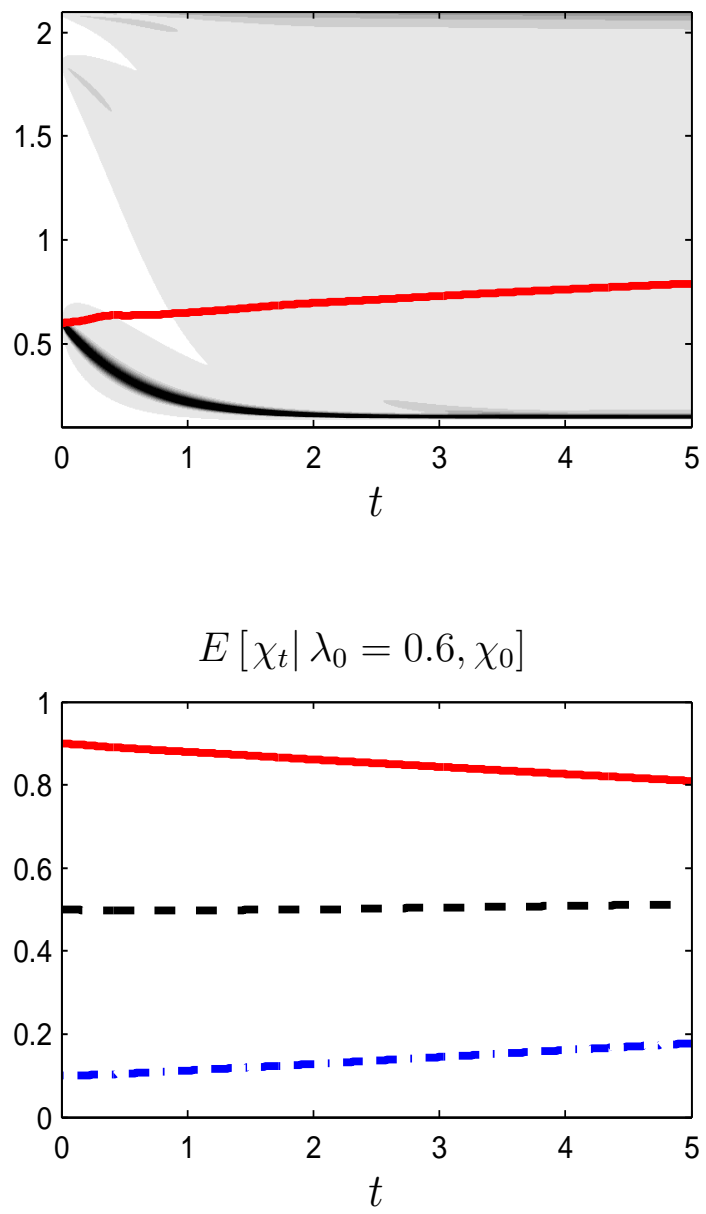

High initial uncertainty

$$
E\left[\lambda_{t} \mid \lambda_{0}=1.6\right]
$$
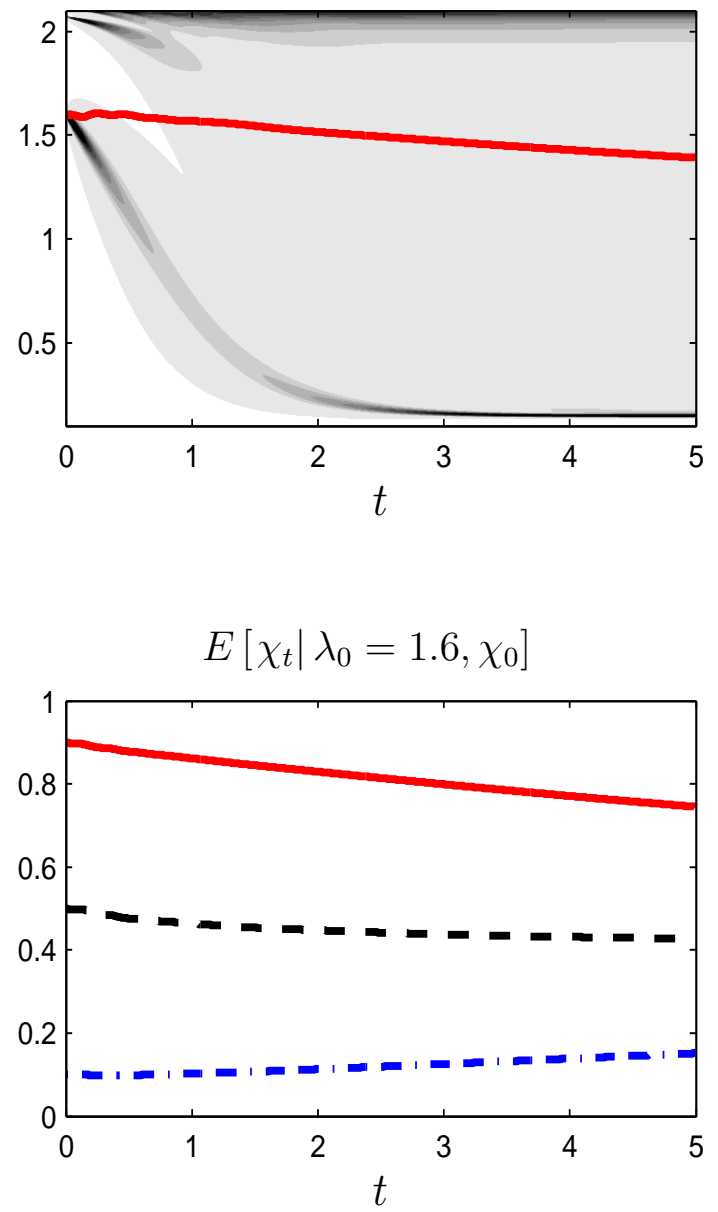

$$
\text { - }-\chi_{0}=0.1 \quad-\text { - } \chi_{0}=0.5 \longrightarrow \chi_{0}=0.9
$$




\section{Figure 3. Collateral runs}

Equilibrium haircuts, capital structure, funding costs, and prices for economies with (no markers) and without (circle markers) a shadow banking sector. The capital mix is fixed at $\chi=0.5$. Haircuts are defined as one minus the collateral value of the asset, e.g. $1-\left(1-\kappa_{\pi}^{a}\right)\left(1-\kappa^{a}\right)$.

\section{Haircuts}

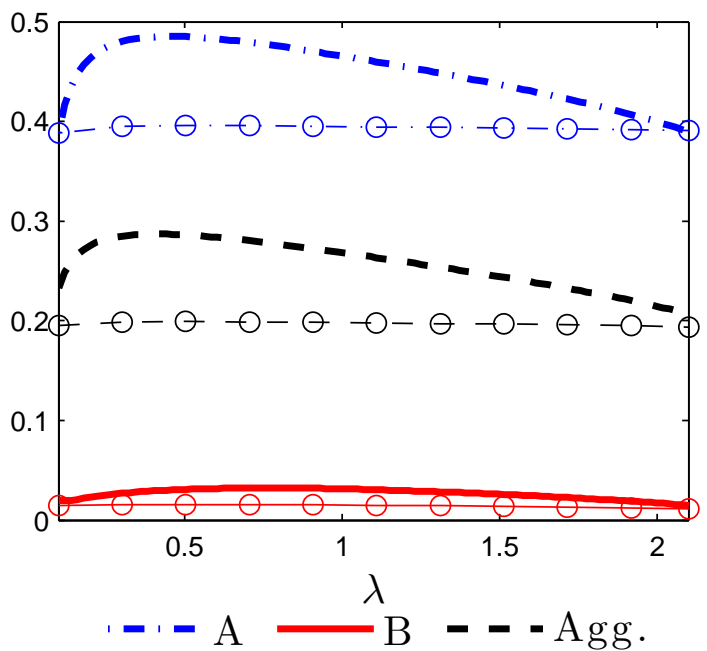

Funding costs

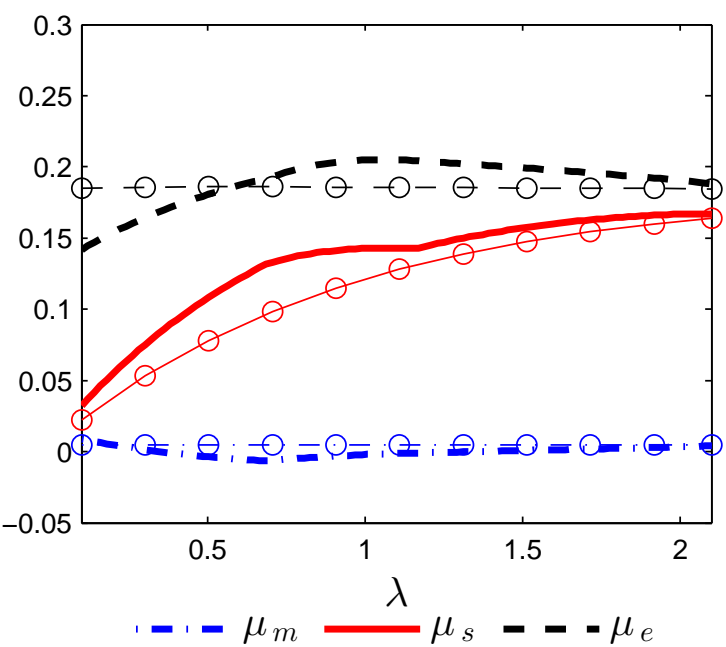

Capital structure

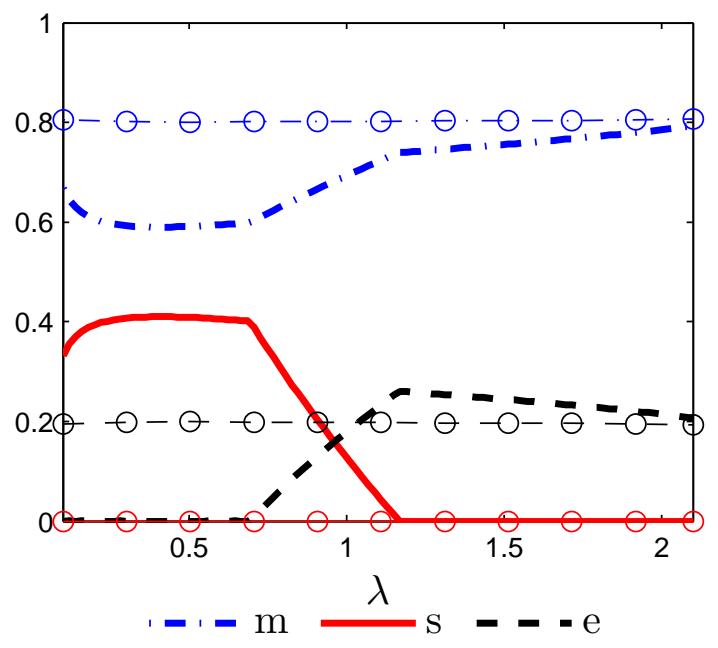

Prices

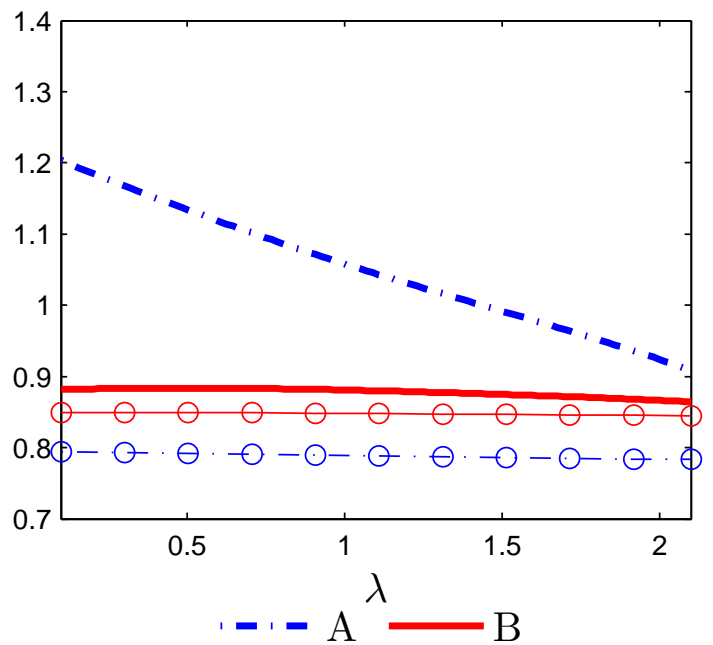


Figure 4. Flight to quality

The yield on money, the spread between shadow money and money (the safety spread), the equity premium, and the crash-return of type- $B$ capital for the model with a dispersion shock $\kappa_{i}^{a}=0.6$ (see discussion in section 3.4), $\mu=0$ and $\eta=2.8$.
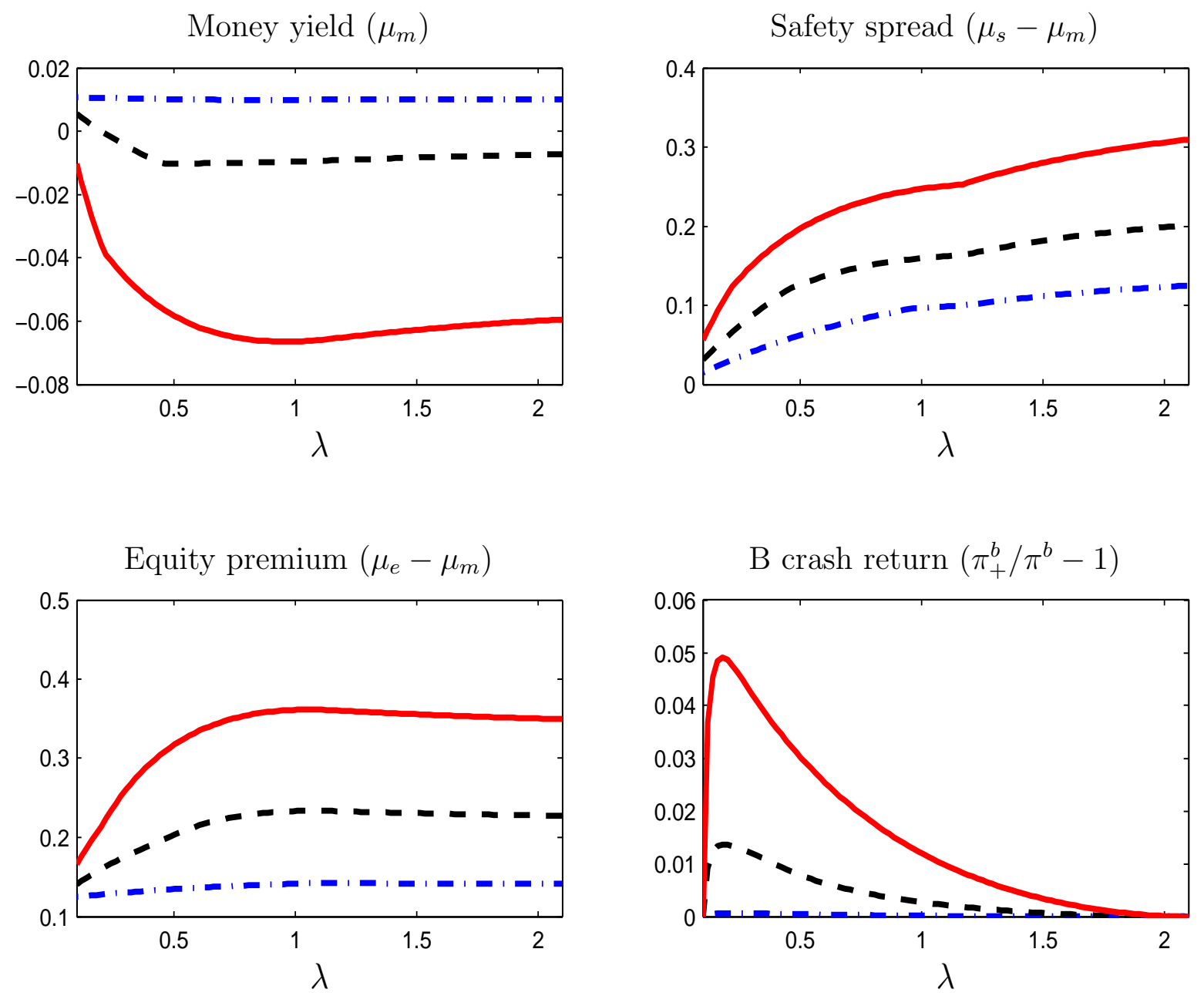

$$
\boldsymbol{- 1} \chi=0.1 \quad-\quad \chi=0.5-\chi=0.9
$$


Figure 5. Asset purchases (LSAP)

In an asset purchase (LSAP) intervention, the central bank buys risky capital and sells safe capital. Here, LSAP lowers the risky asset share $\chi$ by 0.2 , it arrives with $50 \%$ probability after a crash, and it is withdrawn at a 10\% intensity rising to $100 \%$ in the last two panels. The announcement effect compares returns in crashes with and without an LSAP. The ex ante effect compares prices in economies with and without the possibility of LSAP. See Appendix F for details.

Announcement effect on price of $\mathrm{A}$

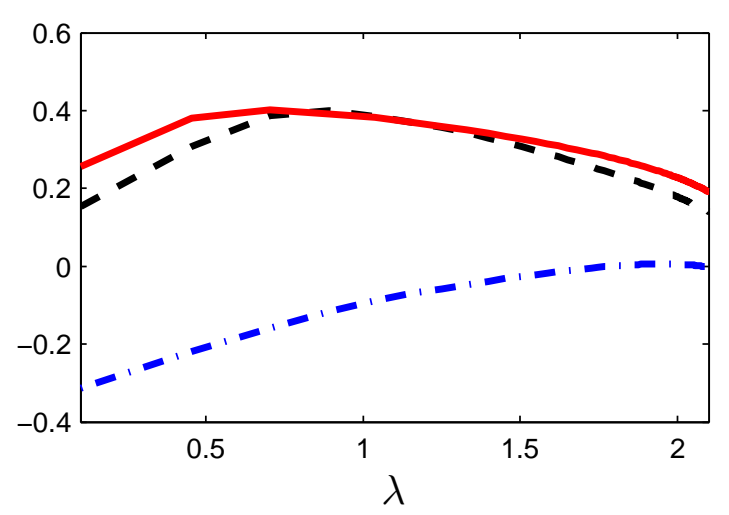

Ex ante effect on price of $\mathrm{A}$

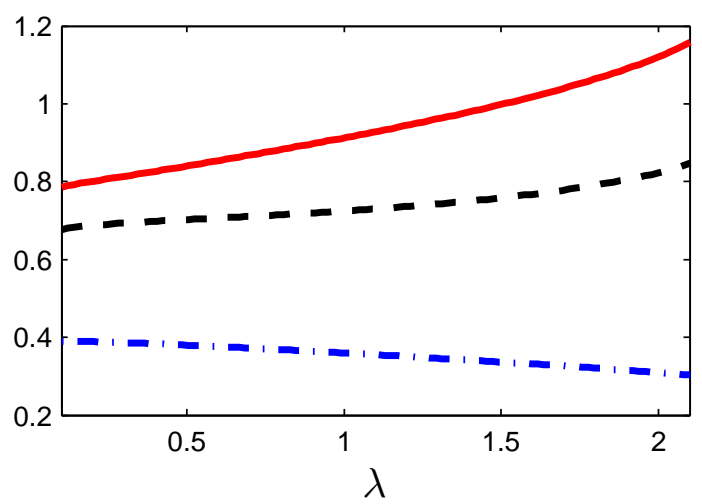

Taper shock effect on price of $\mathrm{A}$

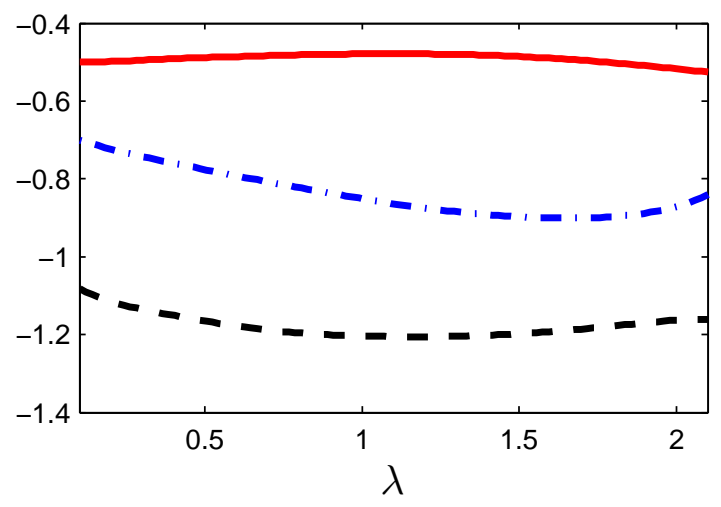

Announcement effect on price of $\mathrm{B}$

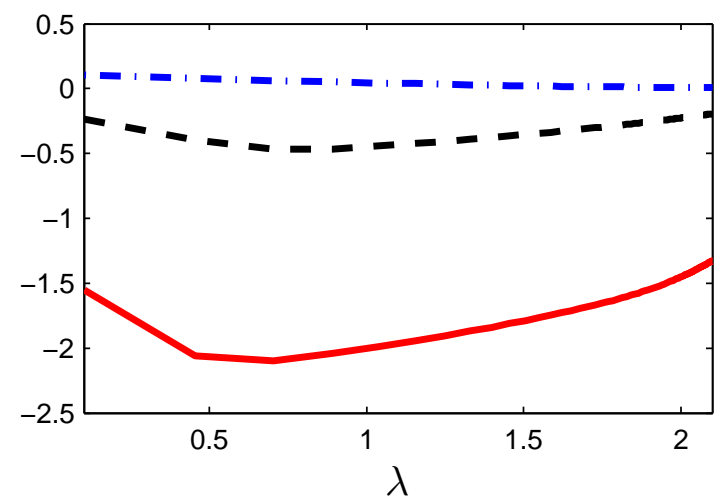

Ex ante effect on price of $B$

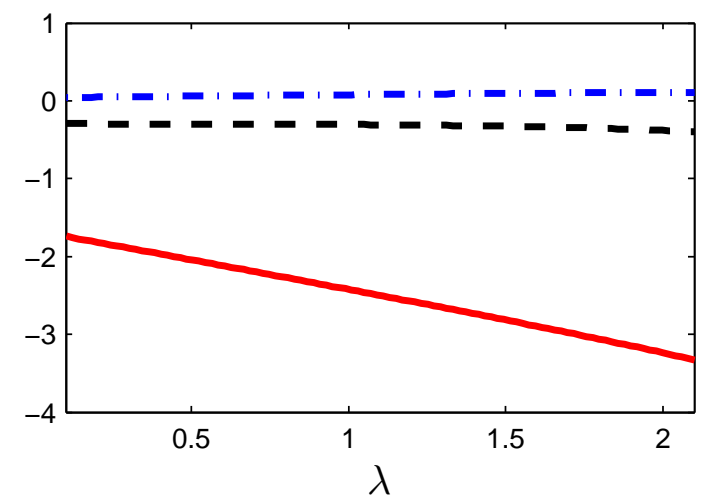

Taper shock effect on price of $B$

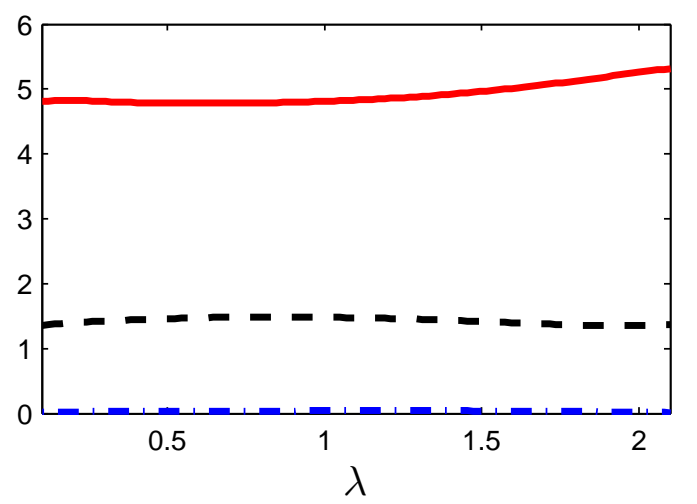

$$
\boldsymbol{-}, \chi=0.1 \quad \boldsymbol{-} \chi \quad \chi=0.5 \quad \chi=0.9
$$




\section{Figure 6. Operation Twist}

This figure shows the effects on prices and pledgability of changing the mix of safe government bonds from fixed-coupon (long-duration) bonds to floating-rate (zero-duration) bonds. The top left (right) plot shows the change in the price of the risky $A$ (long-duration safe $L B)$ capital $\pi_{t}^{a}\left(\pi_{t}^{l b}\right)$, and the bottom plot shows the change in aggregate pledgability $1-\kappa_{A, t}$. This figure uses the parameter values from Section 3.4 to generate strong flight to quality and $\mu=0$ to keep growth invariant to the government's debt structure. Quantities on the vertical axis are in percent.

Change in the price of risky A capital

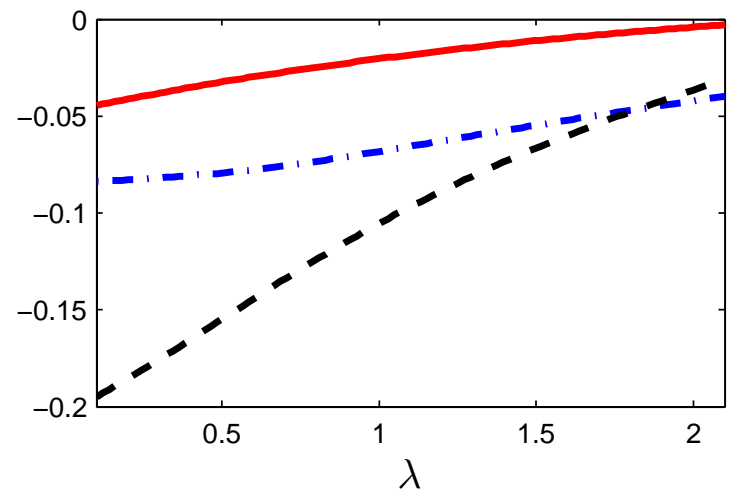

Change in the price of long-duration safe LB capital

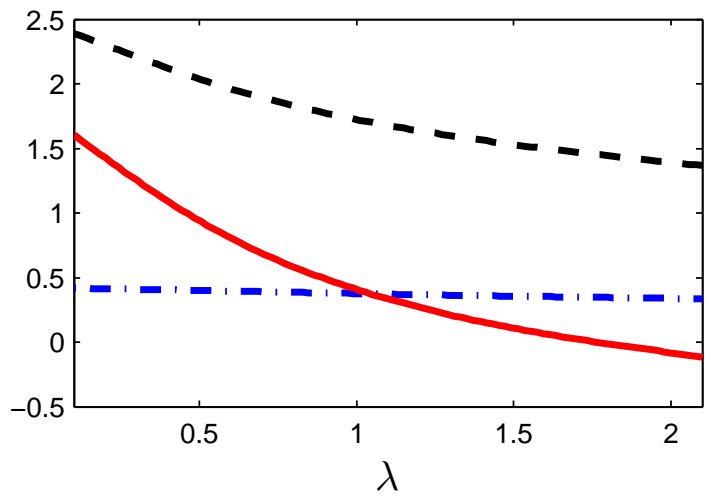

Change in aggregate pledgability

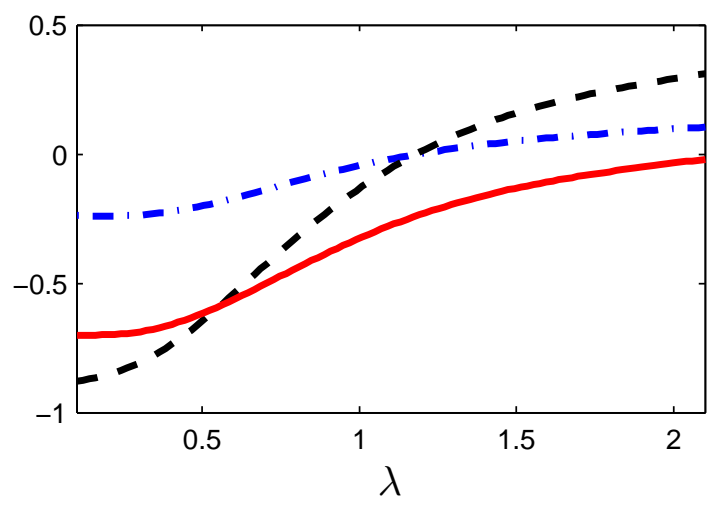

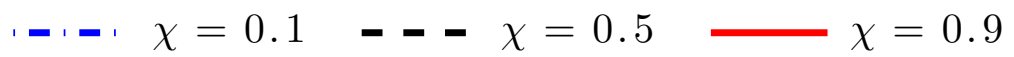




\section{Figure 7. Capital Requirements}

This figure shows the effects of an announcement of higher future capital requirements on prices and intermediary capital structure. Specifically, each plot compares a given quantity across two economies: an economy in which higher capital requirements are expected to be imposed within five years $\left(\beta_{C A P I T A L}=0.2\right)$, and a benchmark economy with no current or future capital requirements. The anticipated capital requirement is set to $\underline{e}=10 \%$. Quantities on the vertical axis of the top panels are in percent, and in absolute quantities for the bottom panels.

Announcement effect on price of $\mathrm{A}$

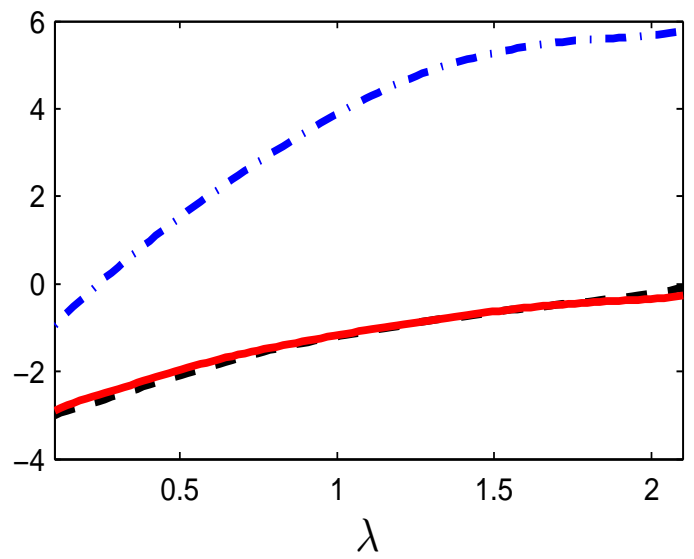

Policy effect on equity capital

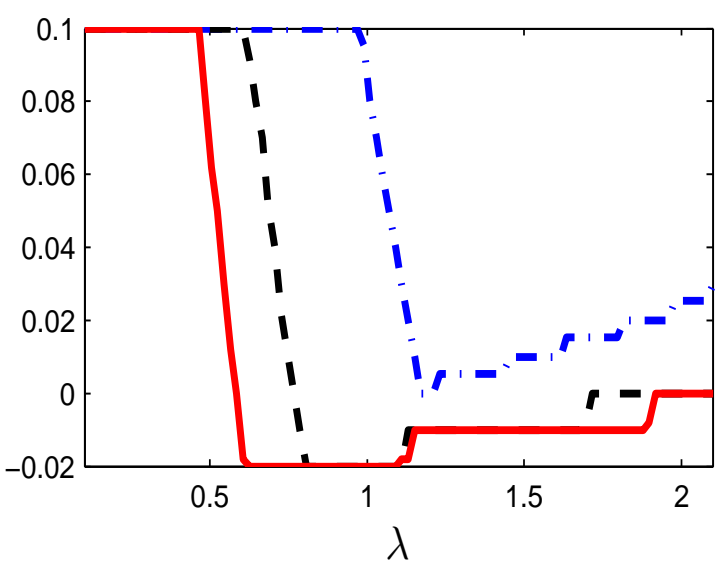

Announcement effect on Price of B

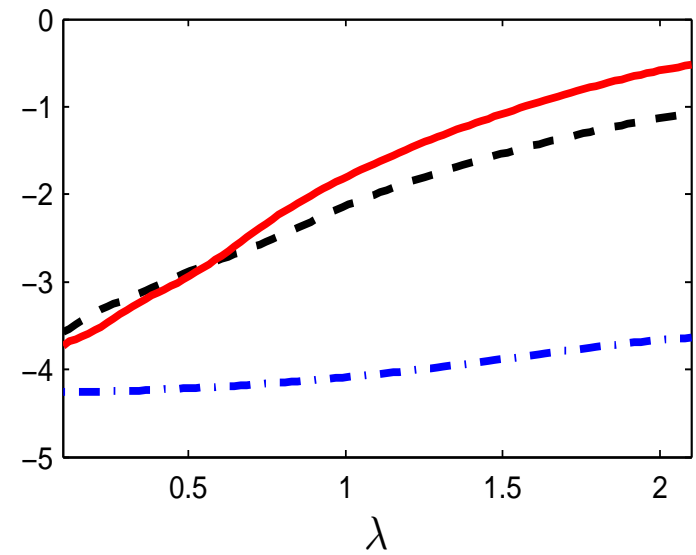

Policy effect on shadow money

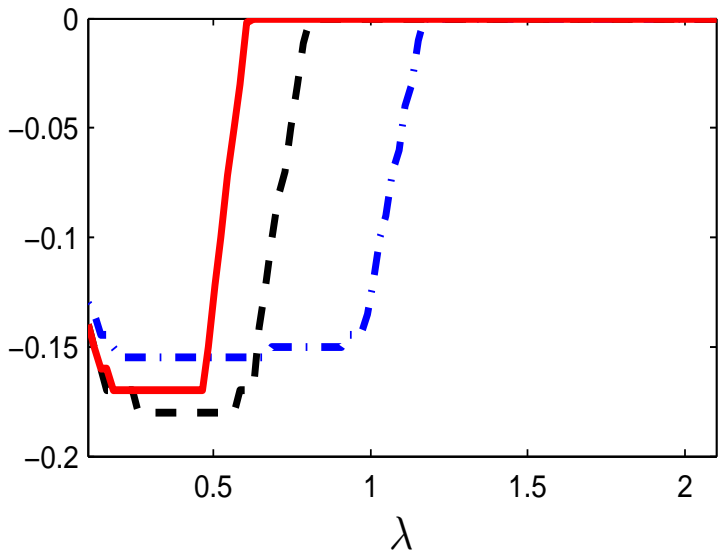

$$
\boldsymbol{- \boldsymbol { - }} \chi=0.1 \quad-\boldsymbol{\chi} \chi=0.5 \longrightarrow \chi=0.9
$$

